\title{
THE PURPOSE OF PUBLIC ART IN THE CANADIAN SUBURB: AN EVALUATION OF MARKHAM'S PUBLIC ART PROGRAM
}

\author{
By \\ Rayson Wong \\ B.ES., University of Waterloo, 2011 \\ A Major Research Paper \\ Presented to Ryerson University \\ In partial fulfillment of the requirements for the degree of \\ Master of Planning \\ in \\ Urban Development
}

Toronto, Ontario, Canada, 2014

(C)Rayson Wong 2014 


\section{Author's Declaration}

I hereby declare that I am the sole author of this major research paper. This is a true copy of the major research paper, including any required final revisions, as accepted by my examiners.

I authorize Ryerson University to lend this major research paper to other institutions or individuals for the purpose of scholarly research.

I further authorize Ryerson University to reproduce this major research paper by photocopying or by other means, in total or in part, at the request of other institutions or individuals for the purpose of scholarly research.

I understand that my major research paper may be made electronically available to the public. 


\title{
THE PURPOSE OF PUBLIC ART IN THE CANADIAN SUBURB: AN EVALUATION OF MARKHAM'S PUBLIC ART PROGRAM
}

\author{
(C) Rayson Wong 2014 \\ Master of Planning \\ in \\ Urban Development \\ Ryerson University
}

\begin{abstract}
Public art is a creative placemaking tool to enhance the quality of civic life and foster a sense of community. There is growing enthusiasm for public art to be integrated into the suburban environment in fostering a more culturally vibrant place. This paper explores the unique challenges faced in suburban public art planning. The City of Markham’s new public art program is used as a case study.

Successful public art in the suburb should reflect the local community's history, values, or needs. Public engagement and collaboration is critical to creating public art that garners intrinsic connections. Generally, since suburban municipalities have smaller populations and lower developmental demand than urban cores, they should incorporate a variety of funding tools to effectively sustain their public art programs.

Markham should increase its efforts on engaging the public in all aspects of public art commissioning, and maximize their financial resources in order to increase the presence of its program.
\end{abstract}

Key words: Public art; suburbs; public art planning; public art program; Canada 


\section{Acknowledgements}

This major research paper is completed with generous contribution from several individuals.

First of all, I would like to express gratitude to my research supervisor, Dr. Zhixi Zhuang, who provided vital guidance and support throughout the process, especially with conceptualizing the framework for the paper. I would also like to thank Corinna Ghaznavi, the public art coordinator for the City of Markham, for evaluating, and providing valuable feedback as a second reader. Lastly, my family’s support cannot be understated during my time at the School of Regional and Urban Planning. Thank you for encouraging me to do my best, and for all the little things that have shaped me into who I am today. 


\section{Table of Contents}

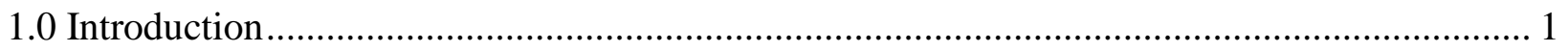

2.0 Public Art in the Suburbs Literature Review ………............................................................. 3

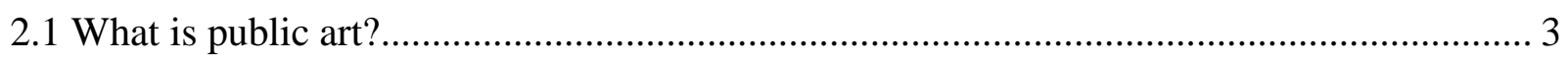

2.2 Why public art matters (placemaking) .............................................................................. 5

2.3 Public art in the suburbs ................................................................................................. 7

2.4 Creating a successful public art program .................................................................... 9

2.5 Gaps in the literature ................................................................................................. 11

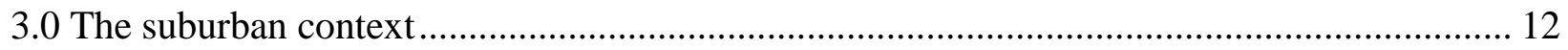

3.1 Low density, auto-oriented strip development............................................................... 13

3.2 Newly master-planned neighbourhoods/New urbanism ..................................................... 14

3.3 Marginalized neighbourhoods................................................................................... 15

4.0 Functions and roles of public art in the post-modern Canadian suburb .................................. 16

4.1 Bringing out meaning in an otherwise mundane environment ........................................... 16

4.2 The slippery slope of public art as place branding ........................................................... 17

4.3 Public art to regenerate................................................................................................... 18

5.0 Essential considerations for suburban public art planning ………......................................... 21

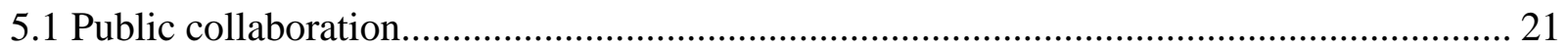

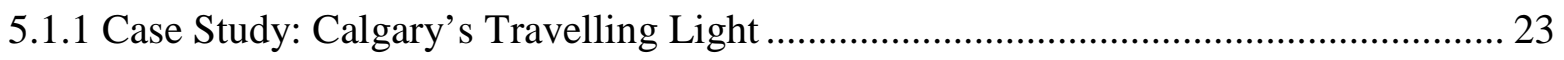

5.1.2 Case Study \#2: Grassroots murals in Washington DC .................................................. 24

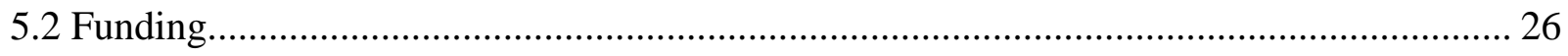

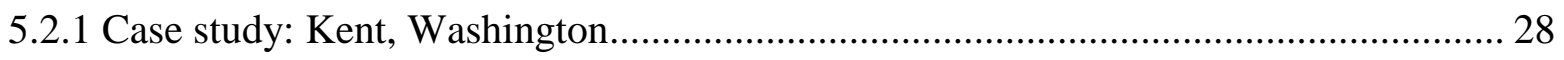

5.3 Emerging trends in funding public art........................................................................ 28

5.3.1 The Grantmaking Revolution ...................................................................................... 29

5.3.2 Fundamental shift in thinking about public art funding ............................................... 30

5.4 Spatial distribution: Equitable distribution or clustering of public art? ............................... 31

6.0 An evaluation of Markham’s public art program .................................................................. 33

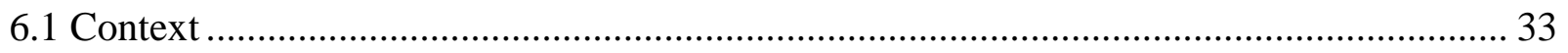




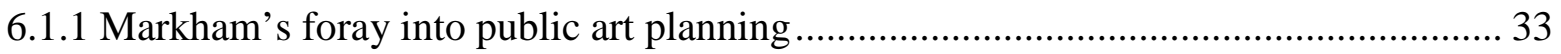

6.1.2 Markham’s Public Art Policies.............................................................................. 34

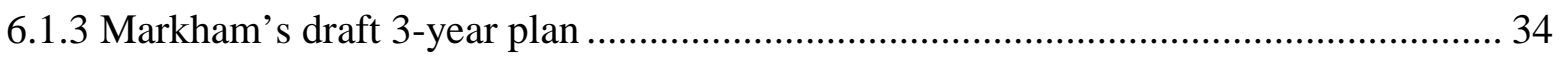

6.2 Evaluating suburban public art programs: methodology .............................................. 35

7.0 Analysis \#1: Public involvement and collaboration ...................................................... 36

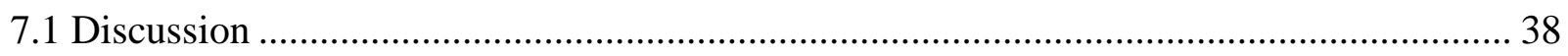

7.1.1 Lack of community involvement in the selection phase ....................................... 38

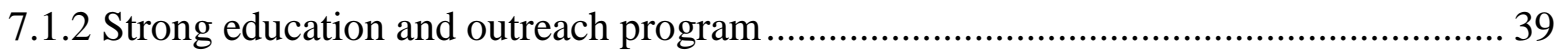

7.1.3 Great opportunity for public art that collaborates with the public ............................ 40

7.2 Recommendations for public collaboration .......................................................... 41

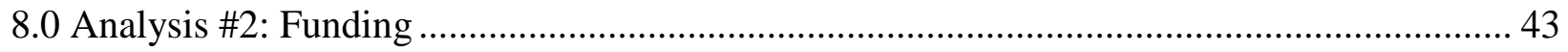

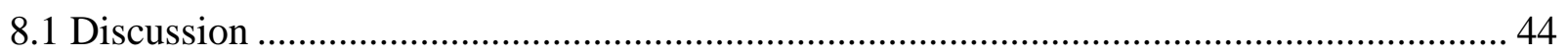

8.1.1 Securing a reliable and diverse funding base ....................................................... 44

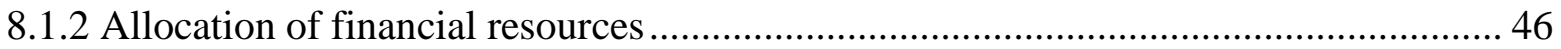

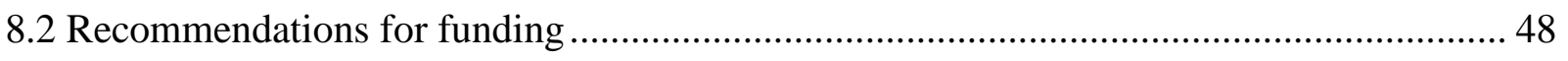

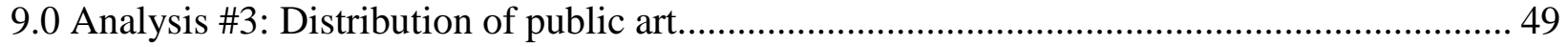

10.0 Future directions for Markham’s public art program ................................................. 50

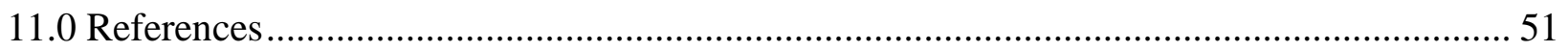




\section{Lists of Tables and Figures}

Figure 1: Heidelberg Project, by Tyree Guyton, Detroit............................... 3

Figure 1: Functional public art in Toronto........................................ 4

Figure 2: The Gates by Christo and Jeanne-Claude: A series of vinyl gates along 23 miles of pathways in New York City....................................................... 7

Figure 4: Cloud Gate by Anish Kapoor, Millenium Park, Chicago........................ 8

Figures 5 and 6: A typical low density suburb catered to the automobile.................. 14

Figure 7: A new urbanist community in Markham, Ontario............................. 15

Figure 8: New genre public art in Washington, DC................................ 19

Figure 9: Calgary's Travelling Light has resulted in criticism over the city's public art

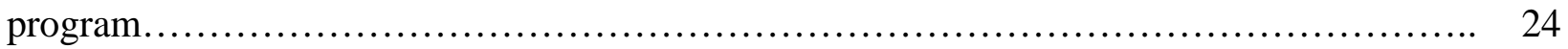

Figure 10: A mural collaborated with survivors of domestic violence..................... 25

Figure 11: A mobile app to locate public art locations in Canberra, Australia................ 40

Figure 12: Edmonton open source street art........................................ 41

Figure 13: Distribution of its annual appropriation funds in Markham's public art program... 44

Table 1: Core components of a public art master plan according to Pally (2011) and Hollinger (2011).............................................................. 10

Table 2: Distribution of public art funds in various cities.............................. 47 


\subsection{Introduction}

Sprawl, bland, car-society, lifeless, etc.: These are all prevailing preconceptions associated with the word "suburb". The mass production of the suburb has fashioned entire regions that exude the same look and feel, regardless of where it is situated in the country. This cookie-cutter formula catered for the automobile have over time neglected the fostering of self-identity and character within the urban landscape (Fleming, 2008). However, there is a growing recognition that investment in the arts and culture sector can enhance quality of life by bringing about social and economic benefits to the city and its citizens. As such, the suburbs are increasingly engaged in re-establishing a sense of place through transforming its built form, ultimately influencing the social vitality of a community (Hertel and Keil, 2013).

The integration of public art into municipal planning has been increasingly adopted in North America, starting with Philadelphia in 1959 (Russell, 2004). While it is still an emerging branch of cultural development and planning, municipal public art planning has become an integrated part of city building in almost all major cities across the continent. Public art has traditionally made sense in large city centres where cultural activities and social gatherings occur (Riddle, 2008). In the peripheries of the culturally vibrant city centres however, the growing enthusiasm exhibited by suburbs ambitious in fostering a more culturally vibrant place has local governments scrambling to integrate cultural planning into its agenda. No longer do they want to strictly be stereotyped as boring, uninteresting bedroom communities; rather, they want to bring culture back to where home is. However, the suburbs face unique issues in their attempt to develop a prominent public art profile. 
This paper explores these unique challenges and intends to provide a planning case for public art in the typical post-modern Canadian suburb by discerning why public art matters in a suburban context. It examines the unique functions that public art can play in such urban environments that differ from an established vibrant city core, and suggests critical aspects of public art planning that suburban municipalities must take into account. Lastly, a conversation on how the research and strategies learned can be applied to Markham's fresh public art program will be provided in order to suggest ways to fortify its prominence and impact its particular urban landscape. 


\subsection{Public Art in the Suburbs Literature Review}

\subsection{What is public art?}

While the realm of municipal public art planning is relatively new, the idea that art in public spaces enhances quality of life is not: architects have created beautiful public art in western cities for centuries. However, the growth of the modern city is gradually shifting our understanding of the term public art—and what it encompasses and entails. Hence, it is important to first explore what public art is. Simply put, public art can be described as "works of art created by artists for places accessible to and used by the public” (Becker, 2004; Kao, 2008). However, the associated meanings prescribed to the word "public" and the word "art" of 'public art' have changed over the last few decades (Goldstein, 2005; Miletic, 2010). Traditionally, art in the public realm has been largely depicted in the form of sculptures and statues commemorating great heroes or events, or portraying common socio-political goals in open public spaces such as parks and plazas (Beardsley, 1981; Kao, 2008). These types of public art are known as public art in public places (Lacy, 1995). Kao (2008) and Russell (2003) propose that while public art can still exist in this fashion, the scope of what we understand public art to be has expanded. One example is the rise of public art as public space — where the site serves as the inspiration for the art piece, which in turn creates a symbiotic interaction between site and form.

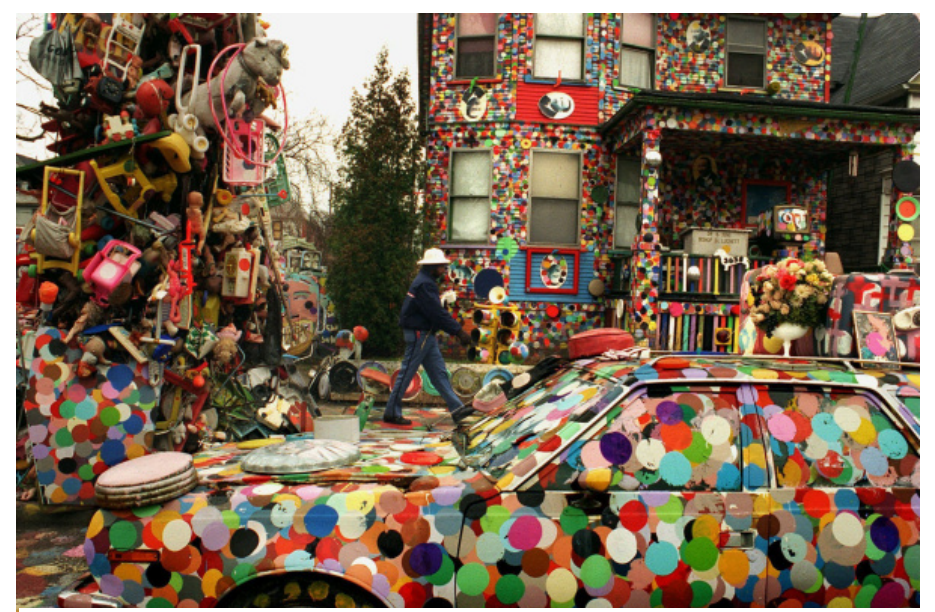

Figure 1: Heidelberg Project, by Tyree Guyton, Detroit (source: disbatch.com. n.d.) 
Unlike gallery pieces, which are portable and displayable in various settings, site-specific art draws attention to a particular place and the context surrounding it. A second example is the expansion from monumental art that honours significant people and events to expressive art that

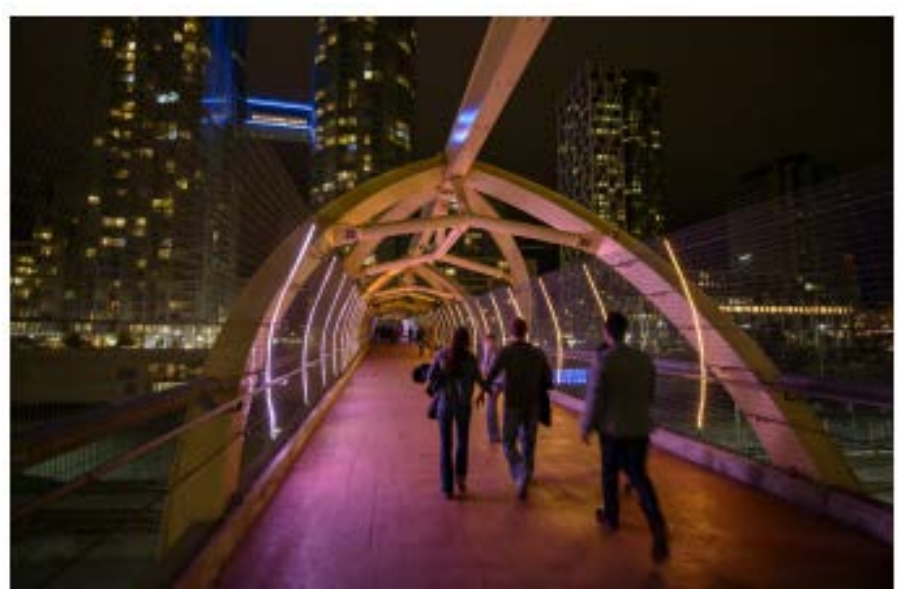

Figure 3: Functional public art in Toronto (source:

Roffelsen. 2013) stimulates dialogue and builds intrinsic connection--known as public art in the public interest (Lacy, 1995). In addition, Russell (2003) recognizes a growth in functional art which is creative, aesthetically pleasing works that also can be used to complete a task or serve a useful purpose.

There are contending viewpoints with regards to the 'public' part of public art however. Some authors broadly consider any art that is located in a public space accessible to the general public to be within the domain of public art (Becker, 2004; Fleming, 2005; Stephens, 2006); while others maintain that for it to be truly public art, it must also provide an intrinsic connection with the public (Rodriguez, 1998; Goldstein, 2005). Lastly, Finkelpearl (2001) argues that because the word 'public' garners an implied association with the lower classes, while 'private' tends to be associated with the privileged. Since the realm of art, or at least those who consume it, historically has been linked with the rich, public art must aim to break this boundary and truly be integrative to the general public. 


\subsection{Why public art matters (placemaking)}

Understanding why public art matters in the urban fabric is critical to advancing the public art agenda. There is a general consensus in the literature that the primary function of public art is to enhance the quality of civic life and sense of community (Beardsley, 1981; Nikitin, 2008; Miletic, 2010; Sussman, 2013). Becker (2004) further distinguishes the overarching goal of public art into four responsibilities:

1. to engage civic dialogue and community;

2. to attract economic benefit and attention;

3. to connect artists with communities, and;

4. to enhance public appreciation of art.

It is suggested that in order to achieve the goals of public art, public art projects need to contribute to 'placemaking' in order to procure the most economic and social value to a community (Florida, 2008; Spayde, 2012; Hollinger, 2011). Like public art, the term 'placemaking' has different meanings for different people. Generally, placemaking is described as the "art and science of developing public spaces that attract people, build community by bringing people together, and create local identity...It is the creation of a built environment that creates community, stimulates interaction, encourages entrepreneurship, fosters innovation, and nurtures humanity” (Spayde, 2012). In this definition, it is evident that public art—while not the only tool, plays an important role in creating a successful place.

The role of public art in fostering economic and social well-being in a community becomes even more explicit and imperative under the notion of 'creative placemaking'—a term coined in 
recent years by Ann Markusen and Anne Gadwa (2007). Markusen and Gadwa (2007) define creative placemaking as strategically shaping the physical and social character of a place through art and cultural activities in order to make substantial contributions to local economic development, liveability, and cultural industry competitiveness. The importance of creative placemaking is also echoed by Richard Florida, a prolific urban theorist and a strong advocate of the creative economy base. In his book Who's Your City he recognizes that public art plays a critical role in creating an authentic sense of place in addition to serving as a tool for revitalization (Florida, 2008). Florida argues that public art, which increases the aesthetics of a community, is vital to attracting and securing an innovative and creative workforce, which is key to a successful community today.

If public art plays such a significant role in placemaking then it is important to understand how this can be accomplished. First of all, Spayde (2012) and Kent and Nikitin (2011) are quick to point out that not all art in the public realm automatically contributes to creative placemaking. This is because, as noted earlier, the formula for placemaking is comprised of two parts: creating spaces that interest people, and creating spaces that connect people. It is a relatively simple task to create aesthetically pleasing art installations in public places that attract viewers and act as a gathering place, but the challenging part is for the art to build and bolster an intrinsic connection with its community (Miletic, 2010). To do this, the notion of public art cannot just be art for art's sake, but must also take into account the geographical and cultural context in which it is situated (Miletic, 2010). Only then can public art installations facilitate engagement and foster attachment, thus contributing to placemaking. This can be accomplished with public art installations that meaningfully express and reflect the local community's values and culture, which ultimately stimulates public dialogue and increases civic pride (Rodriguez, 1998). Site- 
specific art is a key tool in evoking meaning specific to a surrounding community.

Correspondingly, Markusen (2007) warns that public art that ignores the history, values, and needs of the community in which it is placed, is unsuccessful public art.

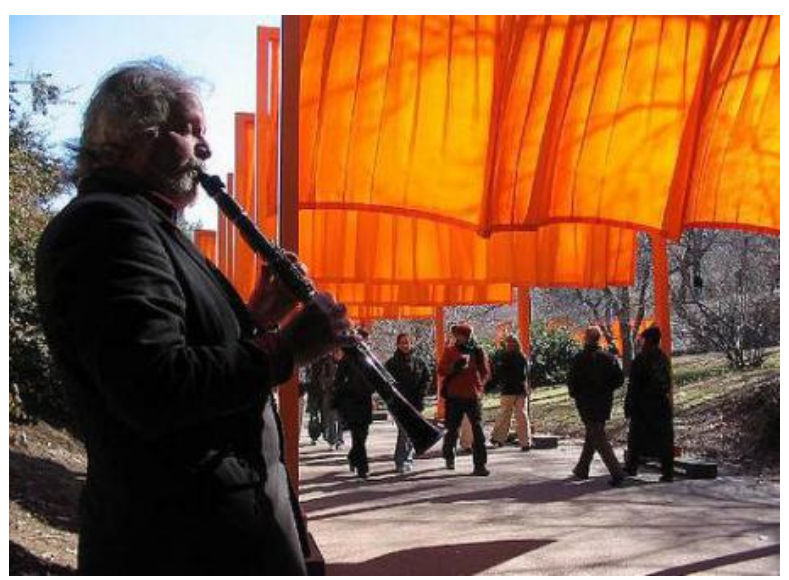

Figure 4: The Gates by Christo and Jeanne-Claude: A series of vinyl gates along 23 miles of pathways in New York City (source: urbanitydesign, 2010)

\subsection{Public art in the suburbs}

Although public art has been a successful component in established city centres, there is a notable lack of public art installations in the suburbs, where public art planning has yet to be prioritized within suburbia (Riddle, 2008a; Nikitin, 2008). Nikitin (2008) argues in her article From Cow Town to Our Town: Is Public Art Part of the American Dream? that this is because historically suburbia has been a representation of placeless-ness: A place designed as a quiet, private place to sleep, away from the hustle and bustle of city life, and away from nosy neighbours. Art, culture, social activity, and public art therefore seemed out of place in the suburban context, where people drive down methodologically built highways through indistinguishable concrete landscapes. As a result, the function-oriented environments of the suburb leave little room for shared public space where community expression and public dialogue flourish (Nikitin, 2008). If placemaking is the primary catalyst for creating a successful 
place where people want to live and play, then public art is a key element for enhancing these banal places in which many suburbanites simply sleep and drive to (Fleming, 2008).

Furthermore, new suburbs created in the form of urban sprawl have little historic value worth preserving and expressing; and community-specific cultural values that can be relevantly expressed have yet to be identified within infant communities (Miletic, 2010; Nikitin, 2008). On the other hand, Florida (2008) contends that public art in the suburb can only be successful and compelling if it is authentic—one that represents the immediate community and highlights its values, history, and uniqueness. Over time these barriers and challenges have cultivated a general disinterest for public art as well as a lack of awareness of the social and economic benefits provided by it (Riddle, 2008a). It is clear then that public art goals and objectives, as well as public art strategies to achieve them, are different in suburban settings when compared to a dense urban environment (Miletic, 2010; Fleming, 2008; Bressi and McKinley, 2008). For example, large-scale, flagship public art developments like Cloud Gate in Chicago's Millennium Park are neither appropriate nor feasible outside of a major urban centre.

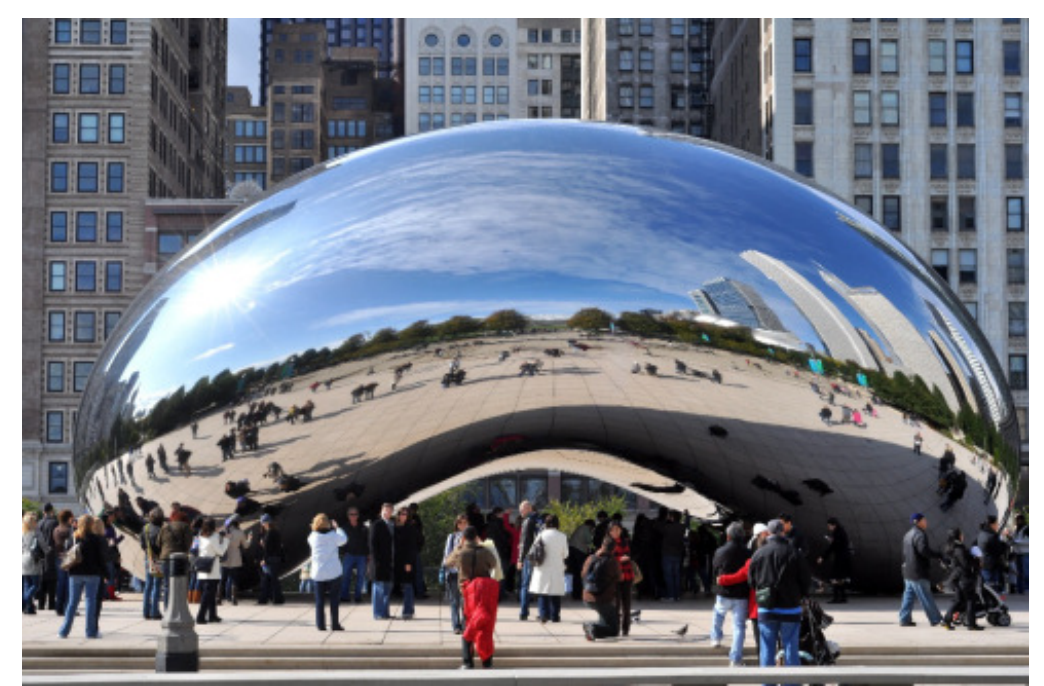

Figure 4: Cloud Gate by Anish Kapoor, Millenium Park, Chicago (source: culturalcapitol.com, 2009) 
In the grand scheme of the current unstable global economic and political landscape, Riddle (2008b) puts the issue of public art in the suburbs into perspective as one that is rather insignificant and low on the urbanization priority list. On the other hand he argues that art has always been a catalyst for proactive societal change. For this reason, Riddle is a proponent for the advancement of public art everywhere, including the suburbs, in order to propel urban life into the future.

\subsection{Creating a successful public art program}

Fortunately, new suburban and urban built form trends are more conducive to a shared public realm, and with that, public art, are emerging (Nikitin, 2008). Bressi and McKinley (2008) address how the public art profile can grow and take advantage of a shifting suburban landscape from single-dwelling residential enclaves to new urbanism built forms. Through their research, they have found that public art in new urban environments have a dual purpose of not only addressing their identity and character, but also shaping and (re)inventing their very own identity (Bressi and McKinley, 2008). The fact that these suburbs are fledgling mean that their cultural conceptions are malleable and can be swayed or even induced by public art works. This has great implications for a public art program in the suburb in terms of ambition and innovation. Addressing the already established suburbs , Ronald Fleming (2008) investigates whether cultural vitality can be elevated through the incorporation of public art in the mature suburb built form, dominated by auto-oriented strip development today. He delivers a set of inquiries for suburbanites and suburban council members to discover more meaning in their communities. Amidst the fervour for creative placemaking, there is now a resurgence of social vibrancy and community connection happening within the suburb, which was once characterized as an escape from social life and community, 
From a logistical standpoint, Barbara Goldstein's Public Art by the Book (2005) offers a thorough guide on commissioning a successful public art program, providing examples of different strategies implemented by municipalities facing different scenarios. In terms of creating a public art plan, Marc Pally (2011) and Jon Hollinger (2011) both identified core components found in public art planning across municipalities of varying sizes in the United States. While Pally suggested nine core elements that should be included in a public art plan, Hollinger recommended twelve, although there are overlapping components that are deemed important in both studies. Hollinger further probes into common practices found in each core component based on his sample analysis as well as the literature on public art and municipal government practices (Hollinger, 2011).

\begin{tabular}{|l|l|}
\hline \multicolumn{1}{|c|}{ Pally (2011) } & \multicolumn{1}{c|}{ Hollinger (2011) } \\
\hline Public art context & Goals and vision \\
Current practices & Integration with other planning \\
Program directions and opportunities & Creating a public art authority \\
Administration Operation & Funding \\
Funding sources & Site selection \\
Community involvement & Artist selection \\
Artist selection and project review & Staffing or contracting program administration \\
Maintenance & Documentation of public art \\
Program review & Maintenance of public art \\
& Acquisition and removal of public art \\
& The receipt of public art gifts \\
& Educational opportunities \\
\hline
\end{tabular}

Table 1: Core components of a public art master plan according to Pally (2011) and Hollinger (2011)

Finally, the Canadian Public Arts Funders (CPAF) is a network that aims to increase the knowledge base amongst the different arts councils in Canada in order to better tackle the social, technological, demographic, cultural, and economic factors influencing cultural services today. It must be noted that the CPAF—-despite its name, is focused on not just public art pertinent to this paper's study, but also encompasses the broader spectrum of the public arts which includes 
cultural services such as music, theatre, dance, etc. Nevertheless, as public art falls under the broader realm of cultural services and activities, much of the information, challenges faced, and best practices shared are relevant.

\subsection{Gaps in the literature}

Although Hollinger’s (2011) and Pally’s (2011) studies reveal core components and common practices in public art master planning, their analysis do not pertain specifically to the suburb, which can face very different constraints than a large city. Hollinger (2011) acknowledges that different communities need to adjust common practices to meet their local needs and constraints. For example, smaller rural municipalities may need to look at a combination of funding tools in order to adequately fund their public art program (Hollinger, 2011).

Overall, little research has been done with regards to public art planning strictly in the Canadian context. That, coupled with the limited amount of literature on public art specifically in the suburban context, means that the overall knowledge base developed for public art planning in the Canadian suburb is scarce. As such, the glaring omission of organized public art planning in municipal affairs has molded a society where public art and its derived benefits have largely gone unnoticed and undervalued. This is only exacerbated in the suburban context, where there is a lack of public realm, and where civic pride and a sense of community are an afterthought. Despite the emerging desire exhibited by several municipal governments ambitious in developing a cultural hub where people want to live in, public art planning in the Canadian suburbs remains in its infancy. 


\subsection{The suburban context}

Canada is a suburban nation, with more people living in the post-war suburbs than in the urban centres (Bain, 2013; Turcotte, 2008). Yet, the concept of suburbia is seldom universally understood and agreed upon. This ambiguity has been exacerbated today, as the line between what constitutes an urban core and the suburb has become blurred. In the movement towards retrofitting the suburb and creating a more vibrant, sustainable urban environment, the Canadian post-modern suburban municipality is experiencing a great shift in its physical and social makeup (Hertel and Keil, 2013; Fiedler and Addie, 2008). For example, Mississauga, Ontario was once undoubtedly a low-density suburban municipality. Fast forward to today, and the same municipality is bustling with dense, high rise developments characteristic of an urban core. Today’s suburb aims toward fostering their own identity.

In the attempt to categorize and put order into the notion of suburbia vs. city, Turcotte (2008) proposes that the suburb be delineated across four categories: Administrative or political boundaries, suburbs as zones outside the city's central core, distance from the city centre, and neighbourhood density. This section of the paper aims to explore emerging trends in public art planning relevant to the various built forms and diverse demographics that exist in a suburban municipality. Since strategy and policy implications, as well as recommendations are geared towards public art planners working for a particular municipality, the term suburb in this paper will refer to the peripheral municipalities outside major city centres. Nevertheless, strategies and examples are drawn from both suburban municipalities and low density areas of major cities. This is because public art planning in the suburbs is a very new albeit rapidly growing phenomenon, whereas cities—especially large American cities, have had much more time and experience honing its craft (Goldstein, 2005). The processes that they undertook to achieve 
public art objectives in neighbourhoods with suburban traits are lessons that can be taken out and applied in a suburban peripheral municipality. However, this brings forth then the need to discern the different types of built forms and social compositions that may exist in a typical Canadian suburban municipality. The following lists several significant urban built forms and developing demographic trends found in a typical suburb that public art planners should take note of. It is by no means an exhaustive list, but is illustrative of a large proportion of today's suburban fabric. Subsequently, the functions of public art in the suburban context are examined, along with an exploration of strategies through a combination of theory review and case study analysis.

\subsection{Low density, auto-oriented strip development}

While the suburban built form is increasingly diversifying, a great portion of the Canadian suburb remains, and will remain, an auto-oriented strip development design (Fiedler and Addie, 2008). Furthermore, despite the resurgence of placemaking qualities in the design of modern neighbourhoods, the reality is that the cookie-cutter but cost-effective, and banal but noncontroversial communities are still being constructed in the form of urban sprawl, albeit in a slowed pace in Canada. These communities, along with the dominant post-war suburban development patterns, are an exemplification of placelessness, described earlier by Nikitin (2008) as places devoid of art, culture, social activity, and a unique identity. 

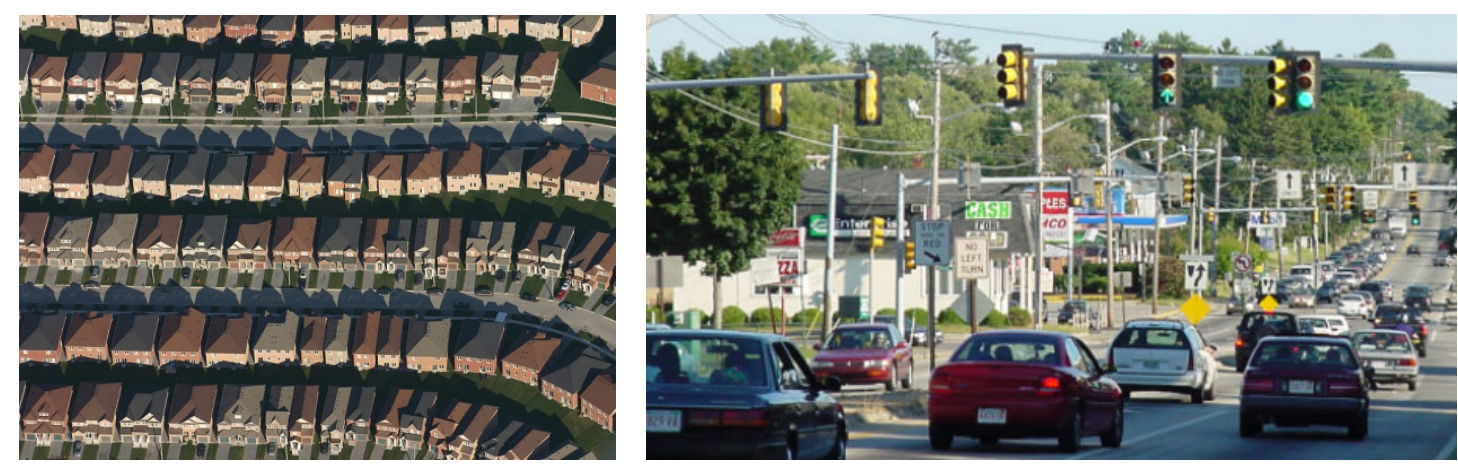

Figures 5 and 6: A typical low density suburb catered to the automobile. (Source: Spaceandculture.org, 2012 and plannersweb.com, 2009)

\subsection{Newly master-planned neighbourhoods/New urbanism}

There is growing awareness that the traditional low-density single-use neighbourhoods, along with technological and generational change have eroded social cohesiveness within the community (Miletic, 2010). Moreover, the overreliance on the automobile as the only viable mode of transport in this typology has contributed to growing issues such as but not limited to traffic, pollution, obesity, and social exclusion (Hertel and Keil, 2013; Bain, 2013; Fiedler and Addie, 2008). In other words, whereas the traditional post-war suburb represented an escape from social life and community, today's suburban communities are eyeing a resurgence back to social vibrancy (Bain, 2013).

In response to this, a new type of neighbourhood built form is emerging in the suburbs that serve to combat these negative impacts on the economic, environmental, and social health of the conventional auto-oriented bedroom communities. Known as the New Urbanism movement, they incorporate higher density, mixed-use neighbourhoods, and transit-oriented developments that offer diverse opportunities for living, working, and leisure. With emphasis on an attractive and animated public realm in a compact form, New Urbanist designs aim to promote a close-knit community by advocating a strong sense of community (Miletic, 2010). 


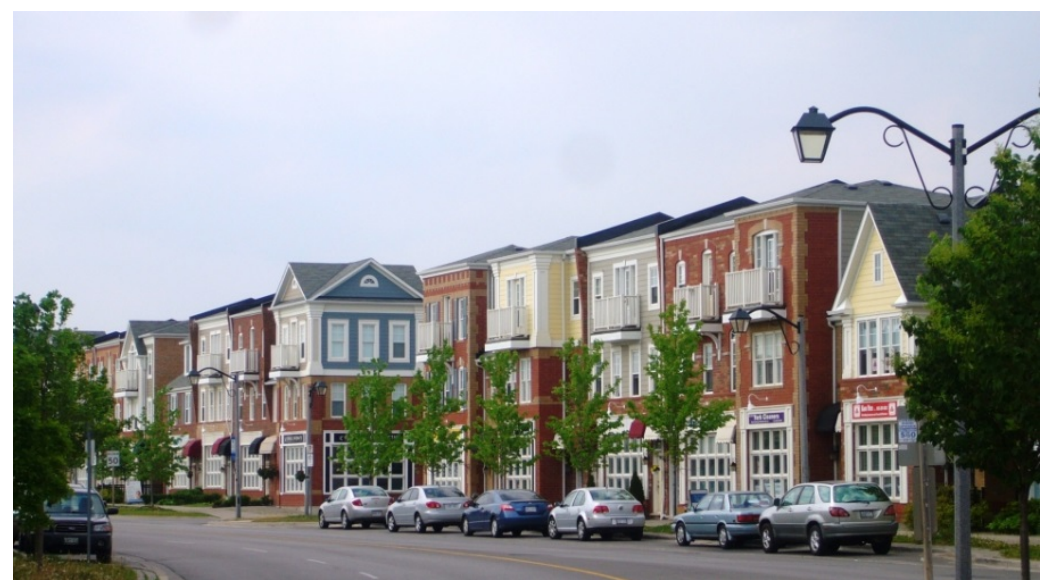

Figure 7: A new urbanist community in Markham, Ontario (source: procenko.com, n.d.)

\subsection{Marginalized neighbourhoods}

Marginalized neighbourhoods are communities in which its inhabitants are disadvantaged in terms of economic or social injustices. Contrary to popular belief, the suburbs are not just home to the middle or upper-class citizens. With urban and socio-economic compositions broadening throughout the suburbs, the issue of homelessness, poverty, and other inequities are also a reality increasing in prevalence in the suburb (Hertel and Keil, 2013). These challenges have also been exacerbated with an ageing suburban infrastructure and rising costs of housing, food, and transportation (Hertel and Keil, 2013). In addition, the suburbs now contain a much more ethno-culturally diverse population than that of the post-war era due to immigration, ultimately forming ethnic enclaves which contain its own set of needs and values (Turcotte, 2008). Overall, there is therefore a need to recognize and address the diverse demographic trends occurring in the suburban landscape. It is important to ensure that people of diverse cultural backgrounds, low-income residents, disabled, etc. are not systemically marginalized or overlooked. 


\subsection{Functions and roles of public art in the post-modern Canadian suburb}

Bearing in mind these physical and social compositions of a suburb, the functions of public art in these contexts can be examined. In other words, what place does public art have in the suburb? The following proposes that public art is indeed essential for the vitality of the suburb as it offers unique ways to improve the municipality’s social and economic well-being.

\subsection{Bringing out meaning in an otherwise mundane environment}

Auto-oriented urban environments greatly lack components that stimulate social interaction and sense of civic pride. As such, there is a dire need for placemaking initiatives in the suburbs wishing to cultivate a vibrant, lively, and successful place to foster a creative economy (Florida, 2008). It has been established that public art as a placemaking feature is a powerful tool to activate and revitalize the homogenous landscape. However, it is also fully recognized that effective public art must be predicated on community values, goals, and aspirations. In a physical landscape dominated by vast parking lots and isolating fencing, how can public art be appropriately conceptualized to foster places that interest and connect people?

The answer lies in digging deep to search for meaning in the everyday functions of suburban life (Fleming, 2008). Fleming (2008) argues that the mere act of living in an environment is teeming with meaning, irrespective of how dull, homogenized, or nondescript the physical environment may be. While meaning may be less apparent in such typographies compared to a dense neighbourhood containing walkable streets and public spaces, it is nonetheless there, waiting to be uncovered, recognized, and appreciated (Fleming, 2008). The role of the public art planner and the artist then are to recognize a place's meaning by identifying the real values that the community holds (Russell and Arefi, 2003). A popular example would be drawing on the history of the place and memorializing themes of the past that served as the foundation of what 
the suburb has become today. Overall, public art can celebrate these seemingly everyday functions of suburban life by animating the physical space that encompasses the banal landscape. The curtailing of urban sprawl due to the Oak Ridges Moraine or Greenbelt Plans in the Greater Toronto Area is an example of something that is worth celebrating or bringing awareness towards through public art.

\subsection{The slippery slope of public art as place branding}

Newly constructed communities in rapidly growing suburbs experience a unique problem in that people moving into such communities have yet to accrue collective cultural values and identities that can be relevantly expressed through public art (Bressi and McKinley, 2008; Miletic, 2010). Nonetheless, Miletic (2010) recognizes that higher levels of civic pride are experienced in newly erected neighbourhoods with a strong focus on public art than in ones where public art is not a priority. In such cases public art is clearly important to the newly constructed landscape. This is where the motive for commissioning public art can run the risk of not fully serving the public good. Developers of newly master-planned communities can potentially use public art as a tool to market their brand and make the place more attractive to appeal to potential buyers (Miletic, 2010). This justification for creating public art has resulted in the construction of public art in the initial stages of development, so that the public art is recognized as a landmark when viewers pass by that particular development (Landi, 2012). This greatly reduces the ability for the public art to meaningfully express local values and identities. It becomes merely a place identifier and a place branding technique. Miletic (2010) suggests that while these types of public art still enhance the aesthetics of the public realm, they garner minimal connection between the residents and public artworks. 
This is not to say that public art should not be a branding or self-promoting technique: In fact, that is one of the fundamental aspects of public art. In addition, a landmark is not less valuable than other placemaking tools. What needs to be dissuaded by public art planners is the inclination to use public art as self-promoting tools for private gains. Instead, public art should be secured to promote for the public good (Landi, 2012). In other words, it is crucial that place branding is not done at the expense of fostering sense of place. This is achieved with strong oversight by the City, in which clear guidelines and goals of public art are established at the forefront to help define what kind of public art or landmark should be created. Through this, public art created early in the development phase can be predicated on maxims and mentalities that are upheld by the suburb as a whole, such as environmental sensitivity, diversity, a hub for hi-tech industries, etc. This allows the municipality to differentiate itself with public art that markets its strengths while also cultivating a sense of place for new residents.

\subsection{Public art to regenerate}

The notion that beauty and art can play a supportive and restorative role for people facing

emotional, social, spiritual, and even physical distress is not new (Nurisah, 2013). Studies have shown that hospital patients in rooms with aesthetically pleasing views have faster recovery times and more positive attitudes as opposed to patients staying in windowless rooms (Ulrich, 1984). This analogy provides evidence that art offers therapeutic qualities and beneficial impacts that permeate into people’s daily lives (Sussman, 2013). Such art that articulates and interacts with diverse audiences about issues experienced by a certain group is a new and emerging branch of public art, known as “new genre public art” (Lacy, 1995) 


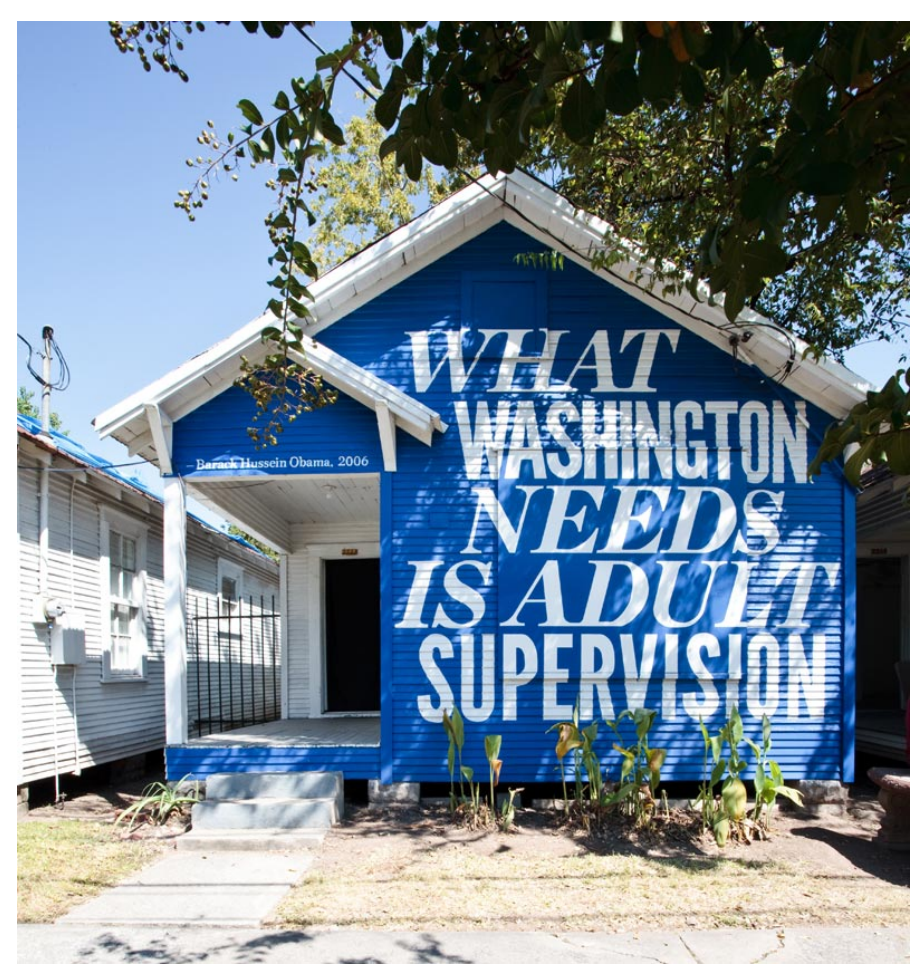

Figure 8: New genre public art in Washington, DC (source: ihculturefront.org. 2012)
Nevertheless, the renewal of a

marginalized community is a long and

enduring process. In order for a

marginalized community to feel socially

included, a community must liberate

itself of its debilitating feelings by

developing a sense of dignity and

empowerment (Kuspit, 1993).

Marginalized people feel disadvantaged

because they often portray collective

feelings of dependency, shame,

deficiency, and self-disdain. The goal for

planners therefore is to create a built environment that advocates and induces constructive feelings of autonomy, sufficiency, and self-respect (Russell and Arefi, 2003). As noted above, benefits for public art include promoting a sense of place, strengthening community bonds, generating economic benefits, etc. For this reason, new genre public art plays a constructive role in the renewal of a marginalized community by giving them a voice, raising their social and cultural profile, and enhancing their collective morale. It should be regarded as "aesthetic activism”: one that induces action amongst the community at large (Russell and Arefi, 2003). However, public art commissioners must recognize that there are two types of activist public art: The art of protest-and-confrontation, and the art of healing-and-renewal (Kuspit, 1993). Public art that protests and confronts through stereotyping can have negative or unintended impacts on the viewers, further severing the connection with the external community. Conversely, the art of 
healing and renewal allows the marginalized community to express their predicaments in a sensitive and humanized way, which ultimately fosters tolerance, empathy, and respect. It is important that public art tend to the latter, through consultation, working with existing organizations, etc. 


\subsection{Essential considerations for suburban public art planning}

Recognizing why public art is a significant element in the suburban public realm is the first step in a suburb's path to distinguishing itself as a new hub of culture through public art planning. The next step is understanding the how-that is, the strategies and policies required to deliver public art in a manner that accomplishes the functions of public art in the suburb. The following describes two vital considerations a public art planner must determine in commissioning public art in the suburb.

\subsection{Public collaboration}

As mentioned above, new genre public art resonates most with the local population, and hence there should be a concerted effort to create these relatable public art in the suburban environment. Logically, a fundamental element of creating this type of public art then is collaboration with the citizens or surrounding community that will be affected most by the project (Russell and Arefi, 2003; Nurwisah, 2013; Bressi, 2012). Public art planners must recognize that one of the greatest assets of any given community is its people. The earlier in the art procurement process that public input can be incorporated, the more likely the outcome will be reflective of their needs (Russell and Arefi, 2003). From the very beginning of the commissioning process, public art planners must be able to first distinguish the resources and the advantages that community already possesses, and determine what socio-economic aspects requires invigorating (Russell and Arefi, 2003). This process is called "asset-mapping”, whereby a list of positive attributes, resources, and advantages are compiled. Accomplished together with the public, this inventory of the community's assets serves to create positive reinforcement within the community, especially for those more accustomed to hearing what is wrong as opposed to what is good in their neighbourhood. 
Contrary to conventional beliefs, the conceptualization and design of the art itself can be achieved through public collaboration as well. In order to understand how the art can meaningfully reflect the community's values and culture, the artist should immerse him/herself in the community for which the art will be situated in (Fleming, 2008). The degree of collaboration can vary on a case-to-case basis: Final say in determining how the artwork will be conceived can either rest with the artist, or on the other end of the spectrum, be directed primarily by the public (Russell, 2004). The former strategy, named "listen-and-lead”, consists of the artist being responsible for creating the final aesthetics of the art, using the thoughts, ideas, and input that the public wants to see developed. The latter strategy, named "confer-and-defer", gives the responsibility of conceiving the art to the public themselves, whereby the artist's role is more akin to a consultant and/or logistic support (Russell, 2004). Regardless of where the level of collaboration lies, both listen-and-lead and confer-and-defer collaboration methods are founded on public input and dialogue from the inside, as well as the ability to detach the artist's ego and preconceived ideas for a collective one that better addresses the community's needs (Fleming, 2008). This is a critical step in ensuring that the art truly serves the needs and interests of the public (Landi, 2012; Notaro, 1995). Lastly, asset mapping and collaboration in the design of the art is especially crucial in the healing and renewal process of especially marginalized populations as it raises awareness of their strengths, which builds self-respect and hope (Russell and Arefi, 2003).

However, a majority of commissioned projects are not necessarily new genre public art. In the commissioning of such conventional public art, the conceptualization and design of the art remains exclusively at the hands of the artist (Goldstein, 2005). Nevertheless, if the goal for public art is to foster creative placemaking and creating spaces that people enjoy and want to 
spend their lives in, some level of public engagement is still necessary (Notaro, 1995). For example, public consultation in the art selection process is a type of public engagement which occurs in the latter stages. Having public input in the selection phase can reduce the chance of implementing unpleasant and/or unsuitable art, as evidenced by Calgary's Travelling Light (described below) (Fleming, 2005). This is especially important for public art projects in privately owned public spaces, where they face a risk of being created for publicity's sake rather than to spur public dialogue (Notaro, 1995). In other words, privately commissioned public art without collaboration may utilize the public art as an attempt to shape people's outlook or approaches to life, or to strengthen brand awareness. This goes against the goals and objectives of successful public art to genuinely create an authentic experience with which the viewers can empathize with the surrounding community. Albeit, most public art programs limit the powers and self-promoting proposals with a jury to ensure a fair adjudicated process.

Overall, public art should find their motivations within the location that they are sited in. While it should not be placed in the public realm to alienate people, this is not to say that public art cannot be provocative, or challenge viewers to see the place they interact with on a daily basis in a different way (Spayde, 2012). The balance between maintaining a critical and creative approach while respecting the parameters of the site and its community to ensure that the intentions of the public art is designed and implemented for the public good is crucial. This is achieved by identifying meaning in an otherwise mundane urban environment and ensuring that the art is reflective of these values.

\subsubsection{Case Study: Calgary's Travelling Light}

Calgary's Travelling Light provides an example of how public art can have negative impacts on its citizens. The 17 metre sculptural ring — designed by a group in Germany, undoubtedly serves 
as a distinct landmark along the city's busy highway, however it has failed to capture the essence of the surrounding community's culture and values. With 95\% of the Calgary Sun's readers voicing displeasure with the project in terms of its aesthetics, appropriateness with the surrounding landscape, and worthwhile use of public funds, the public art project has proven to be unsuccessful in stimulating their once ambitious public art agenda (Dormer, 2013). Instead, its citizens as well as their government have since questioned the city's curating and selection process, citing that money could have been used elsewhere to provide more value (Dormer, 2013). The project adhered to the public art policy's selection process and included design competitions, a short list, and a panel (Dormer, 2013). While this is a well-established adjudication process, due to public discontent, City Council has voted to review its public art policy and increase public engagement in the selection process in order to have a broader conversation around what really works (Kaufmann, 2013).

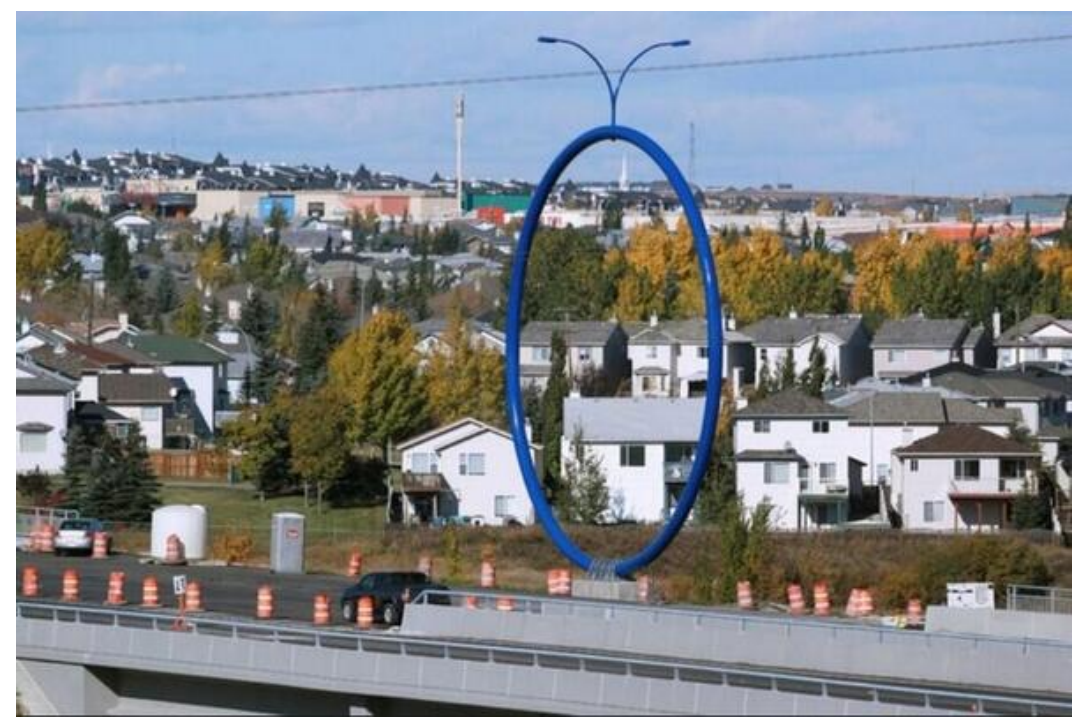

Figure 9: Calgary’s Travelling Light has resulted in criticism over the city’s public art program (source: Huffington Post, 2013)

\subsubsection{Case Study \#2: Grassroots murals in Washington DC}


Joel Bergner — an artist and educator, creates new genre public art through partnerships and collaborations with marginalized groups such as incarcerated youths, people with physical or mental disabilities, the homeless, amongst many others (Bergner, 2013). His work consists of collaborative public murals throughout the world that inform and articulate the local social issues. For example, in his hometown of Washington DC, he worked in conjunction with several refugees coming from countries facing armed conflict to share and educate the community on the quandaries of their home country. Another work featured collaboration with three survivors of domestic violence in illustrating the horrible ordeals they went through at home, bringing them to the forefront of people's consciousness (Bergner, 2013). These murals fell in the middle of the listen-and-lead and confer-anddefer continuum, as both the artist and the marginalized groups had a hand in conceiving and painting it. Nevertheless, the artist spent a great deal of time immersed in the lives of those that he wanted to give a voice to.

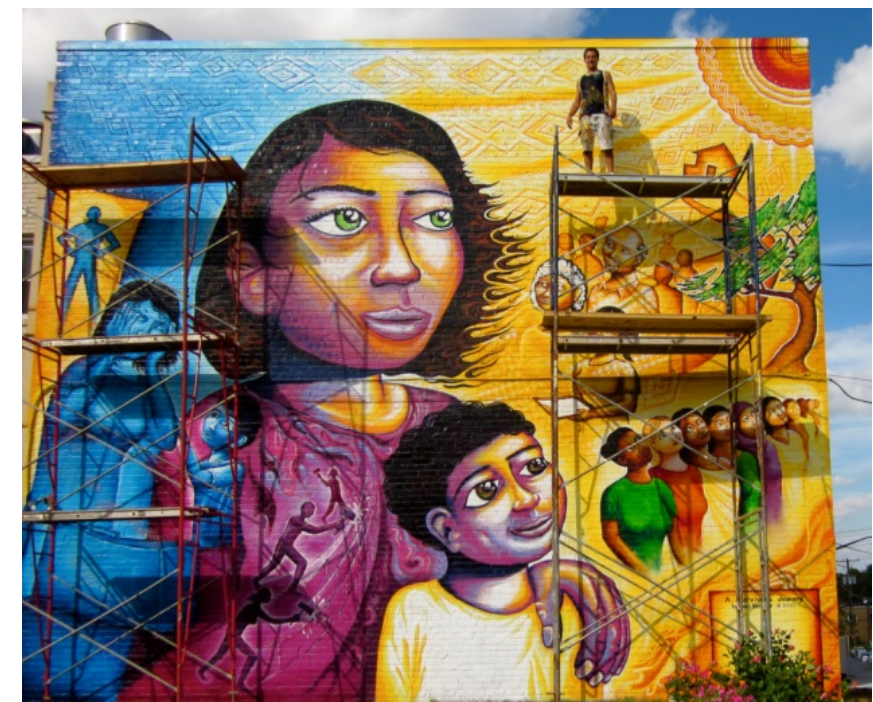

Figure 10: A mural collaborated with survivors of domestic violence (source: Bergner. 2013)

Although Washington DC is an urban centre, Joel Bergner has had success in engaging the marginalized in developing art that further strengthens the understanding and respect between the "haves" and "have-nots". The processes that he undertook to achieve such new genre public art are lessons that can be taken out and applied into the suburban context. For example, these murals do more than simply beautifying the aesthetic qualities of the neighbourhood, they also 
empowered and enhanced the self-worth of the community. The types of engagement with marginalized groups conducted by Joel Bergner nurtures communication and self-expression for people that typically do not have an outlet for their frustrations. When people are given the ability to express their thoughts and perceptions, they are heard by outsiders. This results in less frustration and anger, more self-confidence, and mobilizes and strengthens the community's collective outlook and morale.

\subsection{Funding}

As with all public programs and municipal affairs, funding is one of the most crucial factors for achieving the objectives of the public program — which for the purposes of this paper, means implementing authentic public art across a suburban municipality. Yet, amidst the current unstable global economic landscape, it is also often one of the most crippling factors.

Funding structures used to support a public art program differ greatly in a suburban context compared to a large city. In addition, tools used to secure public art in a municipality also play a significant role in determining where public art is placed. Some funding tools and strategies tend to favour or be more conducive to investment of public art where growth is occurring. On the other hand, funding tools that are not tied to construction or funds that are deposited into a citywide reserve fund can promote equitable distribution (Goldstein, 2005). It is therefore vital for municipalities to recognize which strategy would work best given their circumstances and aspirations. Of course, it is important to note that context is key in every scenario, and different scenarios may necessitate different funding tools. 
A majority of municipalities across North America with public art programs are funded by a “percent-for-art” tool (Hollinger, 2011; Becker, 2004). First implemented in Philadelphia in 1959 , it is a tool which dedicates a percentage-usually around 1 to $2 \%$-of construction costs to the acquisition, maintenance, and management of public art. This method has been the most successful in terms of bringing public art into the public realm. For that reason, it has become the most commonly used funding tool in North America and in Europe in establishing, managing, and maintaining a public art program (Hollinger, 2011).

However, in order for a municipality's public art program to run sustainably through a percentfor-art funding scheme, there needs to be a constant stream of construction projects taking place at a scale where it can be properly funded (Fallon, 2012). This is not the case with many rural suburban municipalities as they simply do not have the population base or growth rate to warrant enough capital projects (Bain, 2013). Overall, unless there is ample growth or redevelopment, a percent-for-art funding scheme cannot be solely relied upon. Smaller suburbs with less growth should look towards other funding tools, or use a combination of funding tools along with percent-for-art to adequately fund its public art program.

Other municipal funding tools include but are not limited to (Becker, 2004):

- $\quad$ Tax-increment financing (See section 6.7.1)

- Hotel/motel taxes

- Diversion of a portion of sales tax revenue

- Foundational grants 
More new and innovative ways municipalities have successfully raised money to support public art include license plate fees in California, a $\$ 1$ golf bag tax in Portland, graffiti abatement funds in Minneapolis, and so on (Becker, 2012).

\subsubsection{Case study: Kent, Washington}

The City of Kent, Washington, a low-population suburb with few construction projects being raised, recognizes the fact that the conventional percent-for-art funding tool alone would not provide sufficient funds to support a successful public art program (Goldstein, 2005). Yet, its citizens and the government were still very committed to raising its cultural profile through public art. In order to accomplish this, the city decided to designate an annual set-aside of $\$ 2$ per resident into its City Art Fund to be subsequently used for commissioning and acquiring art (Goldstein, 2005). This provides the municipality with a steady stream of funds. In addition, it allows the fund to be accumulated and carried over from year to year so that larger projects can be supported by the pooled funds; whereas many initiatives funded by general funds may not have this possibility. Lastly, since the funding is not connected with construction, the city can distribute the funds and place artworks strategically where they can have the greatest impact. The disadvantage of using this model is that it can only grow as population grows.

\subsection{Emerging trends in funding public art}

Since public art planning in the Canadian suburban context is very new, the realm of public art policy making, including funding, is experiencing a high rate of evolution and development. There is a growing acceptance and trend towards funding public art through public-private partnerships (Goldstein, 2005). Usually accompanied by municipality’s percent-for-art tool or other types of government funding models, these public-private partnerships have allowed for a broader spectrum of public art by furthering the ability and capacity to fund more projects. 


\subsubsection{The Grantmaking Revolution}

Grants, donations (both public and private), endowments, gifts, etc. are also an alternative way to fund a public art program. In light of Florida’s (2008) and Markusen and Gadwa’s (2007) influential findings regarding the need to cultivate a creative economy through creative placemaking, the motivation, as well as the viability, to bolster investment in public art has increased from all levels of government, public-private agencies, non-profit organizations, and the private sector (Fallon, 2012). However, this is much more prevalent in the U.S., where there is a history of private endowments and foundations for the arts; although grants are slowly emerging as a viable source of funding here as well (CPAF, 2012). The Edmonton Arts Countil (EAC) is an example of a municipal public art agency which have created a number of different grants (some through partnerships with other municipal departments) to boost their public art profile.

The main drawback for this as a primary source of funding is that it is unsustainable and therefore cannot be relied upon exclusively. Furthermore, since investment implies return, there are concerns with regards to pragmatically counting and assessing the returns that public art can provide (Mahon, 2011). Despite the hype around creative placemaking, there is no accurate way to track and measure a public art program's effectiveness, especially how much economic benefit a place with public art can actually procure, generate, or stimulate, in terms of tangible, countable dollars and cents. Since public art is only one component of placemaking, which in turn functions within an immensely intricate web of societal and planning changes, it is hard to segregate and measure how much effect a public art piece alone has on the community. Lastly, grants may mean that there are fewer controls in place regarding selection and commissioning. Nonetheless, grants have been increasingly used to transform communities through public art. 


\subsubsection{Fundamental shift in thinking about public art funding}

The Canadian Public Arts Funders have identified a range of social, technological, demographic, cultural, and economic factors that are influencing and impacting the current public arts funding system (CPAF, 2012a). Recognizing that public art planners must adapt swiftly to these rapidly shifting factors especially under an environment of global economic uncertainty, new innovative funding frameworks and strategies are required to turn these challenges into opportunities. Fortunately, the public art sector is thriving and increasing in prominence throughout Canada.

The CPAF acknowledged that the current funding system is largely based on the mid-century Ford Foundation approach (CPAF, 2012a). This system measures achievement in terms of audience numbers, budgets, and scales; then puts forth the appropriate funding accordingly. However, it undervalues and discounts the role of external changes and their impacts on the system. These include technological changes—namely, the digital transition, as well as shifting demographics and with that, changing demands and values. This therefore requires a fundamental shift in designing a funding system that not only values growth and tangible numbers as a measure of success, but also the value placed on the social benefits that public art provides (Forgan, 2010). In other words, the funding system needs to adapt and be structured for resilience: One that recognizes the intangible public good and social value-added outcomes public art provides, and one that offers the capacity to adapt to external trends (Evans, 2010). In order to achieve this, art funders must involve the arts community and increase engagement with the public in order to articulate the social relevance of arts and garner more public support (CPAF, 2012a). 


\subsection{Spatial distribution: Equitable distribution or clustering of public art?}

The debate over whether equitable distribution or clustering of public art solicits the most public benefit in the suburb is a highly contested one. There are proponents for both sides and it remains to be seen which strategy is most successful in cultivating a creative culture. On one hand, establishing a "cultural district” where public art are clustered can act as anchors and central locations for where cultural activity and social interaction occurs (Bain, 2013). Just as the concentration of high tech companies in Silicon Valley attract high tech workers and companies, cultural amenities in close proximity has a greater ability to inspire cultural activity and stimulate the creative economy than if individual pieces are spread out across the city (Markusen and Gadwa, 2010). Arlington, Virginia, is an example of a suburb that has focused their public art efforts in several priority areas which have a strong degree of public access and civic identity (Arlington Cultural Affairs, 2004). For them, a hearty growth rate and high levels of public and private investments are prerequisites for public art siting.

On the other hand, public art policies in the suburbs need to cater to the expanding diversity of their population base (Goldstein, 2005). Ideally, public art should be inclusive of the entire community and , as such, everyone should have the same level of access to it. Creating cultural precincts where public art is to be concentrated suggest that other neighbourhoods are not culturally vibrant (Markusen and Gadwa, 2010). This further perpetuates the aesthetic oppression of the banal suburban landscape, and neglects especially low-income marginalized neighbourhoods where there is a need to activate the urban space. Moreover, there is the risk that creating cultural clusters may end up contributing to gentrification (Markusen and Gadwa, 2010). Lastly, Bain (2013) argues that it is unlikely that cultural clusters affiliated with city cores can be equivalently transposed into a suburban context, as she warns that the making of 
culture is incredibly difficult to create from scratch. Rather, culture should be able to spring up organically. Efforts on creating a more dispersed public art profile is also a way to celebrate the multiplicity of publics that create a complex, intricate social fabric full of different culturally distinct neighbourhoods.

Presently, there is not a clear-cut case study showcasing which spatial strategy is most effective in a suburban context. Municipalities can only conduct comparative analyses and past precedents with similar jurisdictions in order to inform themselves of what to undertake (Markusen and Gadwa, 2010). 


\subsection{An evaluation of Markham's public art program}

Armed with ample understanding of the functions of public art in the suburban context, as well as several approaches and strategies to incorporating public art into its landscape to satisfy its diverse populations, this paper now focuses on how the new knowledge can be applied into a developing suburban public art program. The evaluation or review of any given management model is crucial for its success, but it is also the most often neglected component. The realm of public art programming is no exception to this. In evaluating public art programs, the goal is to ensure consistency, determine barriers, and identify opportunities to address the barriers (Usher, 2011).

\subsection{Context}

\subsubsection{Markham's foray into public art planning}

Markham is the largest of nine municipalities in York Region, with a population of over 310,000 (Markham, 2012). Bordering the north-east edge of Toronto, the city is also Canada's most diverse municipality, where $72.3 \%$ of the population are visible minorities (Black, 2013). With the unique task of catering to such a diverse public, the City of Markham must be very flexible, adaptable, and proactive in anticipating future trends. In order to connect and identify with the growing diversity of the city as well as to develop their creative-based economy, Markham has recognized that the development of their arts and culture sector is vital to building a vibrant and liveable community. The Culture Department, created in 2007, embarked on creating strategies to cultivate culture as an integral part of the city's economic and social well-being as it moves forward. The Markham Culture Policy \& Plan was enacted in 2012 which aims to "enhance and 
promote artistic and cultural expressions, to share diverse experiences and to engage people through culture” (Markham, 2012).

Markham’s Public Art Program was initiated in Markham in 2003, supported by the newly formed Markham Public Art Advisory Committee, which serves to represent the residents, neighbourhoods and communities of the City to both staff of the Public Art Program and to Council. In 2012, Markham approved two Public Art Policies_-one for public projects and one for private developments, which outlays the procedures and guidelines for integrating public art into the public realm. Together with the Culture Plan, there is growing recognition that there is a great opportunity to enrich Markham’s built environment with the City’s uniquely diverse and dynamic heritage.

\subsubsection{Markham's Public Art Policies}

Markham’s two policies_ - one for municipal projects and significant renovations, and one for private developers, outline the intentions of Council and the procedures for procuring public art. It highlights the overarching goals and objectives for public art in the city, and the steps required to procure it.

\subsubsection{Markham's draft 3-year plan}

Upon approval of the public art policies in 2012, City Council further requested a three-year public art plan, outlining mainly the operational and administrative duties overseeing the public art program. This paper acknowledges that the draft plan is a working document and has yet to be approved by Council. Furthermore, it is not intended to be a full-fledged, long term master plan, but rather, a short-term plan specific to the course of a 3 year time frame. Due to its intended purposes it is understandable that it may necessarily include all the essential 
components that would otherwise pertain to a comprehensive public art master plan.

\subsection{Evaluating suburban public art programs: methodology}

This section aims to evaluate Markham’s public art program as a whole, which encompasses two enacted public art policies, as well as a newly drafted 3-year public art plan which has yet to be approved by Council. The qualitative review will aim to discover strengths that need to be preserved, and any operational gaps that the City can address going forward. This is done through describing the level of public collaboration that has been provisioned by its guidelines, policies and plan; as well as analyzing their approaches to funding. Successful approaches to these components found in the literature will be used as a basis for determining Markham's efforts on these fronts. Common municipal strategies in both established urban centres as well as successful suburban public art programs will be used as a benchmark in comparison analyses.

It would subsequently determine if any of the suburban public art strategies previously identified can be applied in order to bolster the overall presence of the program and ultimately advance the city’s public art goals. One important factor to consider is that the program has only been recently established. As such, opportunities for improvement may already be recognized by the Culture Department as logical next steps in increasing the program’s reach and status. However, this evaluation and resultant recommendations hope to provide insight and spur discussion into where and how the public art program can advance. It is important to highlight the fact that this is not an appraisal of the social and economic impacts of the public art piece itself. 


\subsection{Analysis \#1: Public involvement and collaboration}

\section{Intended audience}

Determining who Markham’s public art is for can reveal its motivations for implementing public art. Markham's public art seems to be intended for four different 'publics'. The Policy states first and foremost that its public art aims to enhance local residents' quality of life. Secondly, to attract visitors and tourists_-or, the indefinable public, which encompasses the larger, more varied range of demographics and social networks outside of the one the public art immediately serves (Landi, 2012). These two intended audiences are explicitly stated within the objectives of the three year plan, and are achieved through public art as a placemaking tool, enhancing the public realm and quality of life of the surrounding neighbourhood. However, a third, more implicitly specified audience are the financial contributors (both public and private entities) of the program for which the city's public art program is currently being funded. This is achieved through public art as a place branding tool to build marketing leverage, promoting the city as a suburban cultural hub. Lastly, through raising the city’s overall public art profile, Markham’s perpetuation of public art initiatives provide opportunities for artists to get involved, stimulating its creative economy and strengthening its cultural networks.

\section{Public involvement and engagement}

Community involvement in Markham’s public art program occurs on two levels: collaboration, selection, and education and outreach. Community collaboration and involvement is marginal, albeit emerging. For example, the Henderson Bridge mural was a community project: funded by Public Realm and Public Art jointly, supported by Councillor Burke and the Grandview Residents Association. The project was mentored by professional artists who oversaw five younger and emerging artists to realize the project. Lastly, Markham is engaged in design wraps 
for traffic control boxes, in which phase two of the project includes artists working with students of Unionville High School to create additional designs which will be installed throughout the City.

The extent of which the community plays a role in the selection process is minimal. Its policy on municipal projects dictates that the artist or artist proposals are to be selected by a selection jury. This selection panel, which is contracted by the Culture Department, consists of three to five voting members, of which at least one spot may be taken up by a community representative. The role of the community representative, according to the policy, is to ensure that community input is taken into account in the art proposal selection phase. However, selections made by the jury are to be approved by the Public Art Advisory Committee, which consists of one Regional Councillor and nine residents. The Committee has the public's interest in mind, and should they be in disagreement with the jury's selections, they can refuse the project and the process will begin anew. Nevertheless, there is no way for the average person to have a say in the adjudication process.

Interestingly, there are no clearly stated roles for community involvement in the selection of public art by the private sector. In these cases, Markham seeks to have an arms-length selection committee that assesses the artist's qualifications and proposals—similar to that of the municipal public art projects; however, art professionals and the developer are the only required members in the committee. There is no mention of community representatives being a mandatory member of the selection committee in the existing policy for privately acquired public art. Only in the public art plan does it bring up the opportunity of having a local community representative in the selection committee, and only if it is possible. 
Capturing what the public wants in the public art piece happens in the beginning of the process, where community values derived from community consultation and stakeholder meetings are incorporated into the Request for Proposals.

The public art policies identify outreach as a guiding principle, and as such have dedicated a portion of its resources into a comprehensive education and outreach program. They believe that raising public awareness of the program is significant in building an effective and significant public art program. This involves a combination of different initiatives including: Public art lecture series, artist talks, easily accessible and functional website, and public art identifiers. Most recently, the Culture Department organized a free panel discussion consisting of historians, urban theorists, academics, and artists about cultural gardens that animates the public realm. This is one part of a public lecture series that the Culture Department plans on organizing. Their website succinctly highlights the importance of public art, describes current projects, and promotes educational events.

\subsection{Discussion}

The city recognizes the value of community involvement and has acknowledged collaboration, community input and engagement, and outreach as three of the thirteen guiding principles in its public art policies. Presently, while the City is starting to make efforts in community collaboration, only the outreach segment has been adequately realized, and community input in the selection process is lacking.

\subsubsection{Lack of community involvement in the selection phase}

The program has yet to incorporate meaningful community contribution aside from the provision for having one community representative in the selection process. Accordingly, the extent to 
which community values can influence the selection process is slight. The selection process is heavily reliant on a centralized managerial committee which is formed by invitation. While this allows for a variety of representation stemming from different professions (curators, artists, architects, engineers, etc.), they do not represent the local community and their values. Landi (2012) also warns that this highly controlled and deliberated approach is not conducive to a high level of community ownership. If the primary intended audience is for the local residents, it would be sensible to allow them to participate and contribute to the cultural character of their own neighbourhood. This is not to say that a jury consisting of professionals and experts from the field of art is detrimental to producing good public art.

However, Markham can look no further than the lessons learned in Calgary, whereby its Travelling Light generated public outlash directed not just at the artistic merit of the artwork, but at its public art program itself. Despite there also being a community representative involved in their selection process, it became clear that one person alone cannot be the sole voice of an entire community. More public engagement in the selection phase could have prevented them from acquiring something that was inappropriate in the community’s eyes. This can be achieved by having more transparency and opening up the selection panel to the public, where members of the community’s perspectives can influence final decisions.

\subsubsection{Strong education and outreach program}

Education and outreach has been a relative strength of Markham’s public art program early on. Events such as their arts lecture series is a great strategy for raising public awareness of the benefits of public art and Markham's ambition in developing a strong sense of place. Public outreach can be bolstered through increasing its web presence. Markham's public art collection remains fragmented without a comprehensive inventory list for public viewing. While the public 
art plan aims to place signage to create an identifiable network of public art throughout the city, a map showing all the public art projects in the city can bring attention and attract more visitors to various sites.

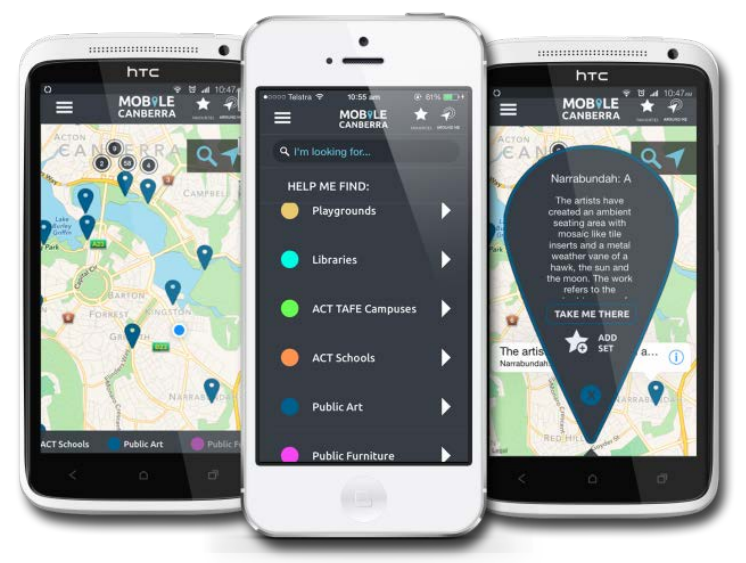

Figure 11: A mobile app to locate public art locations in Canberra, Australia (source: github.com, n.d.)

\subsubsection{Great opportunity for public art that collaborates with the public}

Actual public collaboration and contribution to public art is an area which Markham has just begun to engage in. There are many more opportunities to incorporate the community in the actual creation of the arts early in the acquisition process. As mentioned earlier, the notion of the community gathering, playing, learning, and creating together is one that has incredible potential for reinvigorating marginalized communities (Russell and Arefi, 2003). It is the catalyst for the emergence and sustained presence of culture. Contribution also is a way of educating community volunteers of for example historical knowledge of the city, and provides opportunities for cultural mixing and understanding (Landi, 2012). The congregation of community members who usually may not interact with one another on a day to day basis, albeit being in the same neighbourhood, can always be seen as a success in community building. In addition, the act of participating in a cultural activity such as mural painting can bolster one's 
appreciation for the arts in a public setting. It may also inspire people of all ages to get involved and become a cultural/creative worker.

One way this can be achieved through policy is to enable and encourage more grassroots and informal movements and social action projects such as Joel Bergner’s works (see above). In Edmonton, part of their public art agenda includes sanctioning space for open source art. This is art that allows the community to participate in the creation of the art (Edmonton Arts Council, 2014). While their main rationale for open source art is to curb illegal graffiti tagging, the policy also serves as a channel for which the community can express themselves through art. Slight modifications to the policy can designate space for different community groups and/or social non-profit groups. Nonetheless, there should be active commitment shown by the public sector to commission public art that uses collaboration with the locals as the backbone of the projects (Black, 2011). The driving force of this should not just the artwork, but rather the act of participation itself (Black, 2011; Russell and Arefi, 2003).

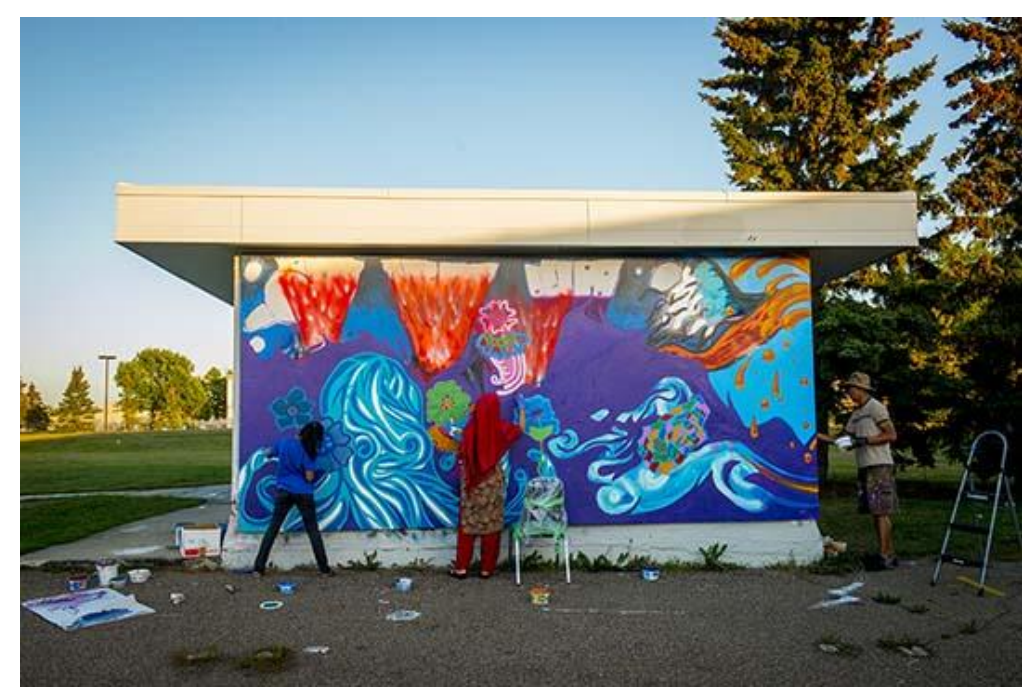

Figure 12: Edmonton open source street art (source: Edmonton Arts Council. 2014)

\subsection{Recommendations for public collaboration}

1. Increasing transparency of selection process: Allow members of the community to participate and provide input. 
2. Continually increase public outreach: provide map of public art inventory to attract visitors.

3. Commission more interactive public art projects that are created by community members.

4. Encourage a deeper level of participation in the arts that is bottom-up (rises from the community). Consider partaking in asset-mapping with community members to recognize strengths in each neighbourhood. 


\subsection{Analysis \#2: Funding}

Currently, funding for Markham's public art program primarily comes from a Public Art Acquisitions Reserve Fund that has been established by Markham to receive cash contributions from both public and private entities. Council has also begun to implement a percent for art scheme in new municipal projects and renovations, starting with the mural in Cornell Community Centre currently nearing completion. However, as per the policy, allocation of a percentage of the construction costs to public art is at the moment a voluntary initiative. In addition, financial contributions cannot be relied upon as a dependable source of funding.

With the increase in prominence and a strong political will to pursue public art planning, the 3year plan provides recommendations that would secure funding through the long-term and in a reliable, sustainable manner. This includes for the provision for the percent for art tool to become a mandatory—rather than voluntary—initiative for all significant municipal construction and renovation projects. In addition to percent for art, the plan calls for an annual appropriation of $\$ 250,000$ from the city’s capital budget. Lastly, other innovative funding tools such as diverting a portion of the gas tax will be explored. Ultimately, the 3-year plan aims to push the public art agenda forward with a more secure foundation for how the program is to be funded.

The new plan also provides a breakdown of how the $\$ 250,000$ annual appropriation is ordained. Note that this is not the distribution of funds for a particular public art project, nor is it the distribution from all accumulated sources of funding. 


\section{Breakdown of annual public art funding}

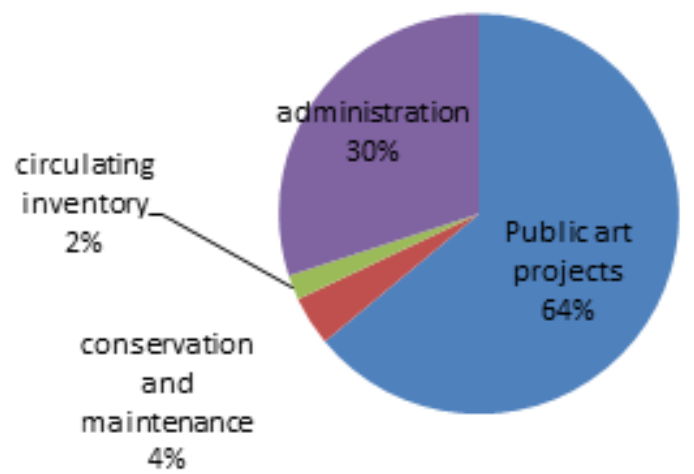

Figure 13: Distribution of its annual appropriation funds in Markham’s public art program

\subsection{Discussion}

\subsubsection{Securing a reliable and diverse funding base}

The volatility of Markham's public art program will remain unstable until it secures a steady and reliable strategy for securing funding. The 3-year plan recognizes this and provided bold recommendations for a steady stream of financial resources. Markham is a rapidly growing suburb experiencing major transformations on its urban built form; and as such, ample funds could be obtained through a proposed mandatory percent for art funding tool. Despite this, it is wise for Markham to maximize its financial resources, especially within existing city budgets through a fixed annual appropriation. Whether this recommended source of funding will be approved and adopted remains to be seen.

As explained earlier, there is a growing amount of public art grants and contributions from both the public and private sector as a response to the growing recognition of the benefits of creative placemaking (Fallon, 2012). Markham should continue to promote positive connections with private development, non-profits, arts organizations, etc. 
Markham can also take advantage of its expanding demand for development by encouraging public art involvement in the private sector through Section $37^{1}$. However, it is important to note that some jurisdictions may provide the capacity to fund public art through these funding mechanisms, while others may not. For example, the Development Charges Act of 1997 in Ontario states that development charges are to be applied to services (Ontario, 2009). In addition, Section 2(4) specifies that development charge by-laws may not impose the provision of cultural or entertainment facilities through development charges (Ontario, 2009). It can therefore be inferred that as public art installations are not a service and that they fall under the umbrella of cultural "facilities", the source of funding for public art would hence be ineligible through development charges in Ontario, although this is still currently up for debate and interpretation. Nevertheless, Toronto has used Section 37 to secure public art to great success.

Another feasible funding tool that Markham may consider is tax-increment financing. Several cities have specially designed agencies dedicated to enrich and enhance cultural amenities such as public art during redevelopment. Los Angeles’s Community Redevelopment Agency (CRA) puts the increase in property tax revenue from properties located within a redevelopment project area back into the community by providing high quality public art (CRA, 2005). However, the disadvantage of using tax-increment financing for public art is that projects would be required to be situated at the site/area of concern (or in redevelopment project areas in Los Angeles). This may further amplify equity and social inequity issues in dilapidating areas where there are no increases in property taxes, and thus no tax-increment financing for public art. To reduce this disparity, other funding tools would still be required to finance public art in such derelict areas.

\footnotetext{
${ }^{1}$ Section 37 of the Planning Act allows municipalities to build higher or greater density than is allowed in the zoning for the provision of community benefits.
} 
Nevertheless, urban renewal financing strategies are emerging as a way to fund public art programs, albeit more prominently in the American context.

\subsubsection{Allocation of financial resources}

While Markham explicitly allocates where its city budget is going towards in running the program itself, its Plan or Policies do not designate how money is to be divided in each public art project. Explicitly dividing up the funds received in each public art project reinforces accountability and transparency. It assures that a majority of the funds are used towards actually producing the public art project itself, while also allocating sufficient amount for the necessary behind-the-scenes costs associated with the commissioning of public art (ie. contracting the jury, request for proposals, etc.). There is currently a lack of literature on determining the optimal breakdown of funds for an efficient and successful public art program—especially for a start-up public art program in a suburban context. However, a quick sample of how different municipalities of varying sizes distribute funds reveals that industry standard for maintenance is set at about $10 \%$, but funds allocated to administration varies. 


\begin{tabular}{|c|c|c|c|c|}
\hline \multirow[b]{2}{*}{ Municipality } & \multicolumn{3}{|c|}{$\%$ of funds allocated to } & \multirow[b]{2}{*}{ Source } \\
\hline & Public art & Administration & Maintenance & \\
\hline Edmonton & 80 & 10 & 10 & $\begin{array}{l}\text { http://publicart.edmontonarts.ca/static_me } \\
\text { dia/pdfs/files/publicart/map.pdf }\end{array}$ \\
\hline Calgary & 80 & 10 & 10 & $\begin{array}{l}\text { http://vancouver.ca/files/cov/CulturePlan- } \\
\text { Phase1-PublicArt-Review-Plan.pdf }\end{array}$ \\
\hline Vancouver & 70 & 20 & 10 & $\begin{array}{l}\text { http://vancouver.ca/files/cov/CulturePlan- } \\
\text { Phase1-PublicArt-Review-Plan.pdf }\end{array}$ \\
\hline Toronto & 80 & 10 & 10 & $\begin{array}{l}\text { http://www.creativecity.ca/database/files/li } \\
\text { brary/pubart_udg_full_18july07.pdf }\end{array}$ \\
\hline Atlanta & 80 & 10 & 10 & $\begin{array}{l}\text { http://www.ocaatlanta.com/wp- } \\
\text { content/uploads/2013/07/Public-Art- } \\
\text { Master-Plan.pdf }\end{array}$ \\
\hline San Diego & 70 & 20 & 10 & $\begin{array}{l}\text { http://www.sandiego.gov/arts- } \\
\text { culture/pdf/pubartmasterplan.pdf }\end{array}$ \\
\hline Portland & unspecified & 27 & 10 & $\begin{array}{l}\text { http://vancouver.ca/files/cov/CulturePlan- } \\
\text { Phase1-PublicArt-Review-Plan.pdf }\end{array}$ \\
\hline $\begin{array}{l}\text { Scottsdale, } \\
\text { AZ }\end{array}$ & 58 & 24 & 18 & $\begin{array}{l}\text { http://vancouver.ca/files/cov/CulturePlan- } \\
\text { Phase1-PublicArt-Review-Plan.pdf }\end{array}$ \\
\hline $\begin{array}{l}\text { Richmond } \\
\text { Hill, ON }\end{array}$ & unspecified & unspecified & 10 & $\begin{array}{l}\text { http://www.creativecity.ca/database/files/li } \\
\text { brary/RH_Public_Art_Policy_June2012.p } \\
\text { df }\end{array}$ \\
\hline Surrey, BC & unspecified & unspecified & $>10$ & $\underline{\text { http://www.surrey.ca/files/Public_Art_Pla }}$ \\
\hline
\end{tabular}

Table 2: Allocation of funds for public art projects in various cities

It is important for Markham to explicitly designate the percentage of all funds collected going into the public art, administration, and maintenance categories. According to Goldstein (2005), the way a municipality designs its funding scheme for public art has a direct correlation on the quality and quantity of the public art.

For example, Seattle provides an example of how even a well-established public art program can face problems with respect to the amount of funding control ordained through its public art policies. While the city's robust and long-standing public art program resulted in a large 
collection of public artworks across the city, its public art policies fail to explicitly state where funding should go and how much should be allocated to different expenses with regards to acquiring, managing, and maintaining artworks (Goldstein, 2005). While this was all well and good during times of prosperity, where increasing amount of artworks were being incorporated into its urban fabric, it presented problems during tight budget years as decreasing proportions of the overall budget went towards actually acquiring the art. Instead, a greater proportion of the budget went towards the more "fixed-cost" aspects of the public art program (eg. project management, maintenance, administration, etc.). Markham can learn from this by adapting a funding strategy that is not so restricted in its nature that it limits the kinds of art that it can commission; yet is flexible enough to allow changes over time.

\subsection{Recommendations for funding}

5. Ensure that a steady and reliable source of funding is secured to sustain the public art program.

6. Maximize the number of financial resources through:

o Promoting positive connections with private development, non-profits, arts organizations, etc.

o Taking advantage of grants and other financial contributions.

o Analyzing the feasibility of:

- Bonusing development incentives (ie. s.37)

- Tax-increment financing

- Other sources of funding

7. Designate the percentage of all funds collected going into the public art, administration, and maintenance categories. 


\subsection{Analysis \#3: Distribution of public art}

Markham`s plan does not explicitly declare priority areas for which public art should be sited, nor is either the strategy of clustering or equal distribution a guiding principle in its policies. A look at the 3-year plan and its projects either currently underway or proposed reveals that the sites for anticipated public art all reside in on-site locations where development or renovations are occurring. This is logical as the program is just beginning to take foot. The integration of public art in new, avant-garde developments can increase awareness and interest from not only consumers of public art, but also financial contributors in the public and private sector. The overall goal in increasing the prominence of public art here is to create a mental shift that beautification of even the most socially barren environments is not a hopeless endeavour (Nikitin, 2008). Enhancing the liveability and aesthetics of the suburb through not only public art, but urban design and other placemaking techniques, can garner a snowballing effect. When arts and culture is at the forefront of suburbanite's consciousness, organic growth of public art will rise from within the community. 


\subsection{Future directions for Markham’s public art program}

Markham's primary focus as of now should be to continue expanding the city's public art profile and raise awareness of the benefits of public art for community building. This in turn would promote more financial investment into the program, as well as garner more demand from the public so that public art becomes an integral part of the suburban environment.

The development of a public art master plan should be heavily considered in the upcoming years. While section 6.1.7 of the Official Plan mandates the development of a public art policy for municipal projects and private developments, the development and adoption of a public art master plan is peculiarly absent. The development of a public art master plan would communicate fundamental decisions and actions that guide what the Markham public art program is, what it does, why it does it, and how it will go about achieving it. Lastly, Hollinger (2011) recognizes that public art programs that have a public art master plan in place experiences a significantly faster growth rate than those that do not.

As the program begins to establish itself as a significant component of planning in the long-term, Markham should not disregard the need to incorporate public art in marginalized neighbourhoods or low-growth areas of the city where social benefits can be most felt. This can be achieved by using pooled resources through either off-site contributions or through funding schemes that are not tied to construction. Efforts to distribute are already being seen, with each ward being allotted two new wrapped traffic control boxes. 


\subsection{References}

Arlington Cultural Affairs. Department of Parks, Recreation, and Cultural Resources, (2004). Public art public places: A public art master plan for arlington, virginia. Retrieved from website: http://arlingtonarts.org/Libraries/Documents/public-Art-MasterPlan.sflb.ashx

Beardsley, J. (1981). Art in public spaces: A Survey of Community-Sponsored Projects Supported by the NEA. Washington: Partners for Livable Places

Becker, J. Americans for the arts, (2004). Public art: An essential component of creating communities. Retrieved from Monograph website: http://www.ncarts.org/SmART Initiative/Tools and Components/Public Art/Public Art-General Resources and Guides/Public Art-Creating Communities.pdf

Becker, J. (2012). Revenue roundup. Public Art Review, 24(46). Retrieved from http://forecastpublicart.org/public-art-review/2012/11/revenue-roundup/

Bergner, J. (2013). Action ashe! global art and social action initiative. Retrieved from http://joelartista.com/action-ashe-youth-mural-projects/

Black, D. (2013). Markham is canada's most diverse community, according to statistics canada. The Toronto Star. Retrieved from http://www.thestar.com/news/gta/2013/05/09/markham_is_canadas_most_diverse_com_un ity_according_to_statistics_canada.html

Bressi, T. \& McKinley, M. (2008). Reflections on public art on the new American frontier. Public Art Review, 20(39). Retrieved from http://www.artfulplaces.com/artfulplaces.com/Blog/Entries/2012/5/21_A_Whirlwind_Surv ey_of_Texas_Suburb-Building_files/PAR39_pp32-36.pdf

Bressi, T., \& McKinley, M. Arlington Economic Development, (2012). Four lenses for looking at the value of public art in arlington. Retrieved from website: http://www.arlingtonvirginiausa.com/?LinkServID=B5485DA3-FB48-FE9989E33E8FD7ED42C0

Canadian public arts funders. (2013). Retrieved from http://www.cpaf-opsac.org/en/default.htm

CPAF. (2011). Future directions in public arts funding: What are the shifts required?. Retrieved from website:http://www.cpafopsac.org/en/themes/documents/CPAF_2011_AGM_Meeting_Re port_xecutive_Summary_Mar082012_000.pdf

CPAF. (2012). Frameworks for innovation in public arts funding. Retrieved from website:http://www.cpaf-opsac.org/en/documents/CPAF-June-2012-MeetingSummaryLeadership-and-Vision.pdf

City of Edmonton (2008). Edmonton Public Art Map - Public Art Master Plan. Retrieved from http://www.edmontonarts.ca/static_media/pdfs/files/publicart/map.pdf 
City of Edmonton. Edmonton Arts Council. (2010) Percent for Art Policy. Retrieved from http://publicart.edmontonarts.ca/static_media/pdfs/files/publicart/epa_policy_suite/C45C.p df

Davey, A. England Arts Council, (2010). Achieving great art for everyone. Retrieved from website:

http://www.artscouncil.org.uk/media/uploads/achieving_great_art_for_everyone.pdf

Dormer, D. (2013). Calgary sun readers slam \$470,000 ring sculpture built on northeast highway. Calgary Sun. Retrieved from http://www.calgarysun.com/2013/10/08/calgarysun-readers-slam-470000-ring-sculpture-built-on-northeast-highway

Evans, R. (2010). Entering upon novelty: policy and funding issues for a new era in the arts. GIA Reader, 21(3)

Fallon, M. (2012). An arts funding revolution: what people are saying about the creative placemaking boom.Public Art Review, 24(47), Retrieved from http://www.writermichaelfallon.com/pdfs/ArtsFundingRevolution-Michael-Fallon.pdf

Fiedler, R., \& Addie, J. (2008). Canadian cities on the edge: Reassessing the canadian suburb. (Doctoral dissertation, York University, Toronto, Canada)Retrieved from http://city.apps01.yorku.ca/wpcontent/uploads/2011/05/file_Canadian_Cities_on_the_Edge-1.pdf

Finkelpearl, T. (2001). Dialogues in Public Art. Cambridge: The MIT Press

Fleming, R. (2008). Finding the there there: Strategies for defining the non-place with public art and urban design. Public Art Review, 20(39). Retrieved from http://forecastpublicart.org/toolkit/images/articleimages/PAR39_pp26-31fleming.pdf

Fleming, R. and Goldman, M. (2005). Public Art for the Public. Public Interest, 159

Florida, R. (2002). The rise of the creative class. New York: Basic Books

Florida, R. (2008). Who's your city? how the creative economy is making where to live the most important decision in your life. Basic Books.

Forgan, D. England Arts Council, (2010). Excellence in the arts. Retrieved from website: http://www.artscouncil.org.uk/media/uploads/achieving_great_art_for_everyone.pdf

Gerin, A., \& McLean, J. (2009). Public art in canada: Critical perspectives. Toronto: University of Toronto Press Incorporated.

Goldstein, B. (2005). Public art by the book. Seattle: University of Washington Press.

Hertel, S., \& Keil, R. (2013). The greater toronto suburban working group. Retrieved from website: http://suburbs.apps01.yorku.ca/wpcontent/uploads/2013/09/GTSWG_REPORT_Inside_L.pdf

Hollinger, J. (2011). Public art master planning for municipal governments. (Martin School of Public Policy and Administration). 
Kao, S. (2008). How can the public art in philadelphia promote the quality of public users' life?. (Master's thesis, Drexel University) Retrieved from http://idea.library.drexel.edu/bitstream/1860/3394/1/SHU-YI KAO.pdf

Kaufmann, B. (2013) Calgary council backs calls to re-sculpt controversial public art policy. Calgary Sun. Retrieved from http://www.calgarysun.com/2013/12/16/calgary-councilbacks-calls-to-re-sculpt-controversial-public-art-policy

Kent, F. \& Nikitin, C. (2011). Collaborative placmemaking: Good public art depends on good public spaces. Public Art Review, (45).

Kuspit, D. (1993). Crowding the picture: Notes on american activist art today. (pp. 255-268). New York: Da Capo Press.

Lacy, S. (1995). Mapping the terrain: New genre public art. Washington: Bay Press. Retrieved from http://www.transart.org/wp-content/uploads/group-documents/65/1363991009Lacy.pdf

Landi, P. (2012). Public art - purpose and benefits: Exploring strategy in the new england city of pittsfield, ma. (Master's thesis, University of Massachusetts Amherst).

Mahon, J. (2011). New funding models in the arts: A case study. , Whitehorse, Yukon. Retrieved from http://www.cpafopsac.org/en/themes/documents/CPAF_2011_AGM_New_Funding_Mode ls_in_the_Art_Mar082012.pdf

Markusen, A., \& Gadwa A. (2010).Arts and culture in urban or regional planning: A review and research agenda. Journal of Planning Education and Research 29, (3), 379-391.

Markusen, A. \& Gadwa, A., Institute on City Design, (2007). Creative placemaking. Retrieved from National Endowment for the Arts website: http://kresge.org/sites/default/files/NEACreative-placemaking.pdf

Miletic, E. (2010). The developer's art: An examination of public art in master planned communities. (Master's thesis, University of New South Wales, Sydney, Australia)Retrieved from http://www.be.unsw.edu.au/sites/default/files/upload/pdf/schools_and_engagement/resorce s/_notes/5A2_47.pdf

Notaro, R. (1995). Art for public places: An evaluation of the city of toronto's public art program. (Master's thesis, Ryerson University, Toronto, Canada).

Nurwisah, I. (2013). Life is beautiful? even the marginalized can benefit from art. Retrieved from http://www.huffingtonpost.ca/-imelda-nurwisah/homeless-artvancouver_b_4172371.html

Pally, M. (2011). The enterprise of process:notes on planning for public art. Washington: National Endowment for the Arts. 
Nikitin, C. (2008). From cow town to our town: Is public art part of the american dream?. Public Art Review,20(39)

Riddle, M. (2008a) Creative Sprawl. Public Art Review, 20(39).

Riddle, M. (2008b) Worlds Away: New Suburban Landscapes. Public Art Review, 20(39).

Rodriguez, J. (1998). Local history, public art and community in an urbanizing suburb. Cultural Geographies, 5, Retrieved from

http://journals2.scholarsportal.info.ezproxy.lib.ryerson.ca/tmp/12107009603356125663.df

Russell, R. and Arefi, M. (2003). Helping to transform community identity with public art: An asset-based strategy for healing and renewal of marginalized neighbourhoods. Chiang Mai University Journal, 2(1), 61-74.

Russell, R. (2004). A Beginner’s Guide to Public Art. Art Education, 57(4).

Spayde, J. (2012). Public art and placemaking: The role of art in making meaningful places. Public Art Review, (47).

Stephens, P. (2006). A Real Community Bridge: Informing Community-Based Learning through a Model of Participatory Public Art. Art Education, 59(2)

Sussman, J. (2013). Art in public spaces. National Civic Review, 102(2). Retrieved from http://journals1.scholarsportal.info.ezproxy.lib.ryerson.ca/tmp/4777220834826719349.pdf

Turcotte, M. Statistics Canada, (2008). The city/suburb contrast: How can we measure it?. Retrieved from website: http://www.statcan.gc.ca/pub/11-008-x/2008001/article/10459eng.htm

Usher, D. (2011). Evaluating public art in the north of England: Logic models, frameworks and emerging impact. Local Economy, 26(3), 203-213. 